\title{
Effects of lesions of the medial parabrachial nucleus (PBNm): Taste discrimination and lithium-chloride-induced aversion learning after delayed and contiguous interstimulus intervals
}

\author{
A. AGÜERO, M. GALLO, M. ARNEDO, F. MOLINA, and A. PUERTO \\ University of Granada, Granada, Spain
}

\begin{abstract}
This article analyzes the effects of lesions to the medial parabrachial nucleus (PBNm) in taste aversion learning (TAL) and taste discrimination tasks (TDT). In the first experiment, control and lesioned rats were presented with a delayed TAL task in which presentation of the gustatory stimulus was followed 15 min later by the intragastric administration of $\mathrm{LiCl}$. In the second experiment, ingestion of the gustatory stimulus was followed immediately by $\mathrm{LiCl}$ administration. Control animals successfully learned both tasks, whereas PBNm-lesioned animals learned only the second task. In the third experiment, the animals were subjected to TDT with water, saccharine, and quinine. The lesioned animals ingested significantly different amounts of stimuli from that ingested by control rats, showing a clear preference for high concentrations of saccharine; the lesioned animals rejected high concentrations of quinine to a lesser degree than did control animals. In a fourth experiment, PBNm-lesioned animals were able to solve a delayed TAL task when discriminated gustatory stimuli were used. These results are interpreted as evidence that the PBNm lesion interferes with gustatory processing and that the temporal demands imposed by Experiment 1 obviate the use of exteroceptive cues.
\end{abstract}

Taste aversion learning (TAL) consists of rejection of gustatory (or olfactory) stimuli as a result of the association of these stimuli with symptoms of gastrointestinal discomfort, nausea, vomiting, and so on (Garcia \& Koelling, 1966; Kiefer, 1985). The process appears to be an example of associative learning, with considerable adaptive value, since it allows the subject to avoid ingesting foods that might reduce the chances of survival. The acquisition of TAL, for which organisms seem to be biologically "prepared" (Garcia, Lasitter, Bermudez-Rattoni, \& Deems, 1985; Grill, 1985; Seligman \& Hager, 1972), is straightforward and rapid. The cerebral mechanisms responsible for the formation of associations between gustatory and visceral cues have been extensively studied (Ashe \& Nachman, 1980; Gaston, 1978; Grill, 1985; Kiefer, 1985); many authors have pointed out that the brain stem is an area where sensorial information from both the gustatory and the gastrointestinal systems converge. This association has been implicated in the control of energetic balance (Contreras \& Smith, 1990; Elizalde \& Sclafani, 1988; Herman, Kohlerman, \& Rogers, 1983; Miller \& Teates, 1986) and in the modulation of feeding behavior (Contreras, Beckstead, \& Norgren, 1984; Norgren, 1983; Novin, Rogers, \& Herman, 1981; Pfaffman, Frank, \& Nor-

This report is based in part on a doctoral dissertation by A.A. submitted to the University of Granada. The authors thank Jesús López Mejias for help in preparing the graphs. Karen Shashok translated the original manuscript into English. Correspondence should be addressed to A. Agüero, Area de Psicobiologia, Depto. de Psicologia, Universidad de Jaén, E-23071 Jaén, Spain (e-mail: aaguero@piturda.ujaen.es). gren, 1979; Radhakrishman \& Sharma, 1986; Schwartz \& Grill, 1984; Sharma, Jacobs, Gopal, \& Dua-Sharma, 1977; Weingarten \& Martin, 1989). Behavioral studies based on these findings (Bechara, Martin, Pridgar, \& Van der Kooy, 1993; Di Lorenzo, 1988b; Grill \& Norgren, 1978; Grill, Schulkin, \& Flynn, 1986) have shown that, under certain circumstances, the brain stem is probably able to generate a pattern of basic feeding behavior that enables the organism to discriminate and respond appropriately to gustatory stimuli and to modulate these responses on the basis of its immediate nutritional status (Grill \& Norgren, 1978). Therefore, the interaction between afferent visceral and gustatory information in the brain stem may well act as a sufficient substrate for some basic behavioral manifestations, as an essential component of these regulatory processes.

One of the brain stem structures that presents all of these features is the parabrachial nucleus (PBN). This nucleus, made up of a medial and a lateral subnucleus (Block \& Estes, 1990; Fulwiler \& Saper, 1984; Voshart \& Van der Kooy, 1981), is involved in visceral information processing (Bechara et al., 1993; Nagai et al., 1987; Pammer, Fodor, \& Palkovits, 1988) and in the transmission of gustatory information toward more rostral structures of the central nervous system (CNS) (Block \& Schwartbaum, 1983; Lasiter, Glanzman, \& Mensah, 1982; Nishijo \& Norgren, 1991; Norgren, 1976; Norgren \& Leonard, 1972; Saper \& Loewy, 1980; J. B. Travers, 1988). The medial PBN (PBNm) has been implicated in the latter function, including the processing of sensory gustatory information (Nishijo \& Norgren, 1991; Perroto \& Scott, 1976; Ya- 
mada, Ohsima, Oda, Adachi, \& Satoh, 1990) and the transmission of gustatory information toward presumably "nongustatory" regions of the brain (Bernard, Alden, \& Besson, 1993; Norgren, 1976; Yonemura, Takei, Kinitake, \& Ishiko, 1989). These connections may be relevant in behavioral processes in which the processing of gustatory stimuli is essential. The PBNm has been shown to maintain connections with a large variety of structures thought to be involved in the acquisition and/or retention of TAL (Fernandez-Ruiz, Miranda, Bermudez-Rattoni, \& Drucker-Colin, 1993; Garcia et al., 1985; Gaston, 1978; Kemble, Studelska, \& Schmidt, 1979; Simbayi, 1987; Simbayi, Boakes, \& Burton, 1986).

On the basis of this background, we initially designed the first experiment to test the hypothesis that animals in which this pathway for gustatory information transmission was surgically interrupted (electrolytic lesion of the PBNm) would have difficulty in discriminating between two gustatory cues-one associated with a neutral substance (isotonic physiological saline, PS) and one a toxic chemical agent (lithium chloride, $\mathrm{LiCl}$ ) - in a standard TAL paradigm in which a $15-\mathrm{min}$ delay (one of the characteristic features of TAL; see Garcia et al., 1985) was introduced between the gustatory stimulus and the intragastric administration of the chemical agent.

\section{EXPERIMENT 1}

\section{Method}

Subjects. The subjects were 16 male Wistar rats weighing 280 $380 \mathrm{~g}$. All animals were housed individually in $30 \times 15 \times 30 \mathrm{~cm}$ cages, which also served as training chambers during the experiment. A 12:12-h light:dark cycle was in effect, with lights on at 0800 . Only 14 of the 16 rats were used in the behavioral procedure due to obliteration of the intragastric fistula. Seven animals were assigned to the control group (sham lesion), and the remaining 7 were assigned to the experimental group (electrolytic lesion of the PBNm).

Apparatus, surgical procedure, and histology. Spouts attached to graduated burettes containing the fluid stimulus were placed, according to the experimental paradigm, through two holes located in the front panel of the cage at the same height and distance from the midline.

The animals were operated on a David Kopf stereotaxic instrument for rats. Electrolytic lesions were made with a Grass DCML5 lesion generator, which supplied direct negative current through a monopolar electrode approximately $200 \mu$ in diameter, insulated throughout its length except for the last $0.5 \mathrm{~mm}$.

The stereotaxic coordinates of the PBNm (A-P, $-1.4 ; \mathrm{L}, \pm 1.7$. $\mathrm{V},+2.1$, from the interaural point of reference) were obtained from the stereotaxic atlas of Pellegrino, Pelley, and Cushman (1979).

Surgery was performed under general anesthesia with sodium thiobarbital ( $50 \mathrm{mg} / \mathrm{kg}$, Lab. Abbot, Spain). The animals were placed in the head holder; immediately thereafter, two microtrepanations $1 \mathrm{~mm}$ in diameter were made to receive an electrode placed over PBNm nuclei. A 1-mA direct negative current was passed through the electrode, over PBNm, for $25 \mathrm{sec}$ in the lesioned group. In the sham group (control group), the electrode was lowered to the surface of the PBNm nucleus, but no current was passed. At the end of the stereotaxic surgical procedure, the electrode was removed and the wound sutured. A $0.1-\mathrm{cc}$ dose of penicillin was injected i.m. (Hoeschst Ibérica, Madrid).

At the conclusion of the experiment, the subjects were perfused intracardially, and the brains were removed and stored in $10 \%$ form- aldehyde for a minimum of $48 \mathrm{~h}$. Electrolytic lesions were located in sections prepared with a freezing microtome and were studied under a light microscope. After histological examination of the brains of the experimental animals, the PBNm lesion was judged to be complete in all of them (i.e., the lesion virtually destroyed the PBNm on both sides of the brain). In all experimental animals, the lesions were confined to the pontine gustatory area (PBNm; see Norgren, 1976) and the adjacent supratrigeminal area; in no case was the motor nucleus of the trigeminus or the mesencephalic trigeminal nucleus affected. The lesions were located in the medial subnucleus described by Fulwiler and Saper (1984). Figure 1 shows the location and extension, in anteroposterior section, of the lesion in experimental animals. The PBNm lesion occupied an area from 0.8 to $1.6 \mathrm{~mm}$ posterior to Reference Point 0 rostrocaudally. The lesion extended rostrally to the appearance of the IV cranial pair. On 1 animal, the lesion extended to deeper levels vertically, but the data obtained with this animal did not differ from the results obtained with the rest of the animals in the group. The lesions never extended as far as the medial end of the brachium conjunctivum and, thus, never affected the locus coeruleus; nor was the brachium itself affected posteriorly (however, for 2 animals, we could not rule out that the brachium had been affected, due to the proximity of the lesion to this structure). The lesions were circumscribed within an area located in the medial half, ventral to the brachium conjunctivum, and never dorsal to this structure, in contrast to the lesions produced in other studies (Bechara et al., 1993; Di Lorenzo, 1988a; Flynn, Grill, Schulkin, \& Norgren, 1991; Flynn, Grill, Schwartz, \& Norgren, 1991; Grigson, Spector, \& Norgren, 1994; Reilly, Grigson, \& Norgren, 1993; Spector, Grill, \& Norgren, 1993; Spector, Norgren, \& Grill, 1992). Moreover, the lesions did not extend to the ventrolateral zone of the brachium and, thus, did not affect the $\mathrm{PBNl}$ or the nucleus of Kollicker.

Behavioral procedure. After surgery, the subjects were allowed 2 weeks for recovery, after which an intragastric fistula was implanted (Silastic Medical Grade Tubing, Dow Corning Co.) according to Deutsch and Koopman's (1973) procedure. One week was allowed for postoperative recovery. After this period, the animals were given 5 days of training. The rats were placed on a $23-\mathrm{h} 53-\mathrm{min}$ water-deprivation schedule and allowed to drink tap water for $7 \mathrm{~min}$ only from two graduated burettes presented simultaneously so that they would learn to drink alternately from both burettes and to avoid the development of positional preferences.

After 5 days of adaptation, the experimental phase was begun, consisting of one daily session during 4 days. Two different gustatory stimuli were available on alternate days. Strawberry (S) and coconut $(\mathrm{C})$ extracts (McCormick and Co. Inc., Baltimore, MD) were diluted in tap water to a concentration of $0.5 \%$. In each of the training sessions, the subjects had access to one of the stimuli during $7 \mathrm{~min}$. Only one of the stimuli (appropriately balanced) was followed by the intragastric administration of $0.15 \mathrm{M} \mathrm{LiCl} 15 \mathrm{~min}$ later (Gruppo Montedison. Carlo Erba, Milan, Italy) ( $50 \%$ of the amount of gustatory stimulus ingested, instead of a fixed amount of toxic agent, to eliminate as far as possible the effects of the greater dilution of $\mathrm{LiCl}$ in the stomach of the animals that had consumed greater amounts of the gustatory stimulus presented). Because no differences were found between the control and the lesioned groups in the amounts of $\mathrm{LiCl}$ administered during the training phase (i.e., in the amounts of gustatory stimuli consumed), these data are not analyzed further in the Results and Discussion sections. The same procedure was used in sessions in which the animals were given the neutral stimulus, except that PS was injected. Half of the animals received the $\mathrm{LiCl}$ injection 15 min after drinking $\mathrm{S}$; the other half received $\mathrm{LiCl}$ administration after drinking $\mathrm{C}$. The sequence of the sessions and position of the burette were suitably balanced.

After two trials (4 days), the choice test was presented. The choice test was divided into two phases. In both groups, Test 1 consisted of the simultaneous presentation for $7 \mathrm{~min}$ of two burettes containing the same gustatory stimuli that had been associated with $\mathrm{LiCl}$ dur- 


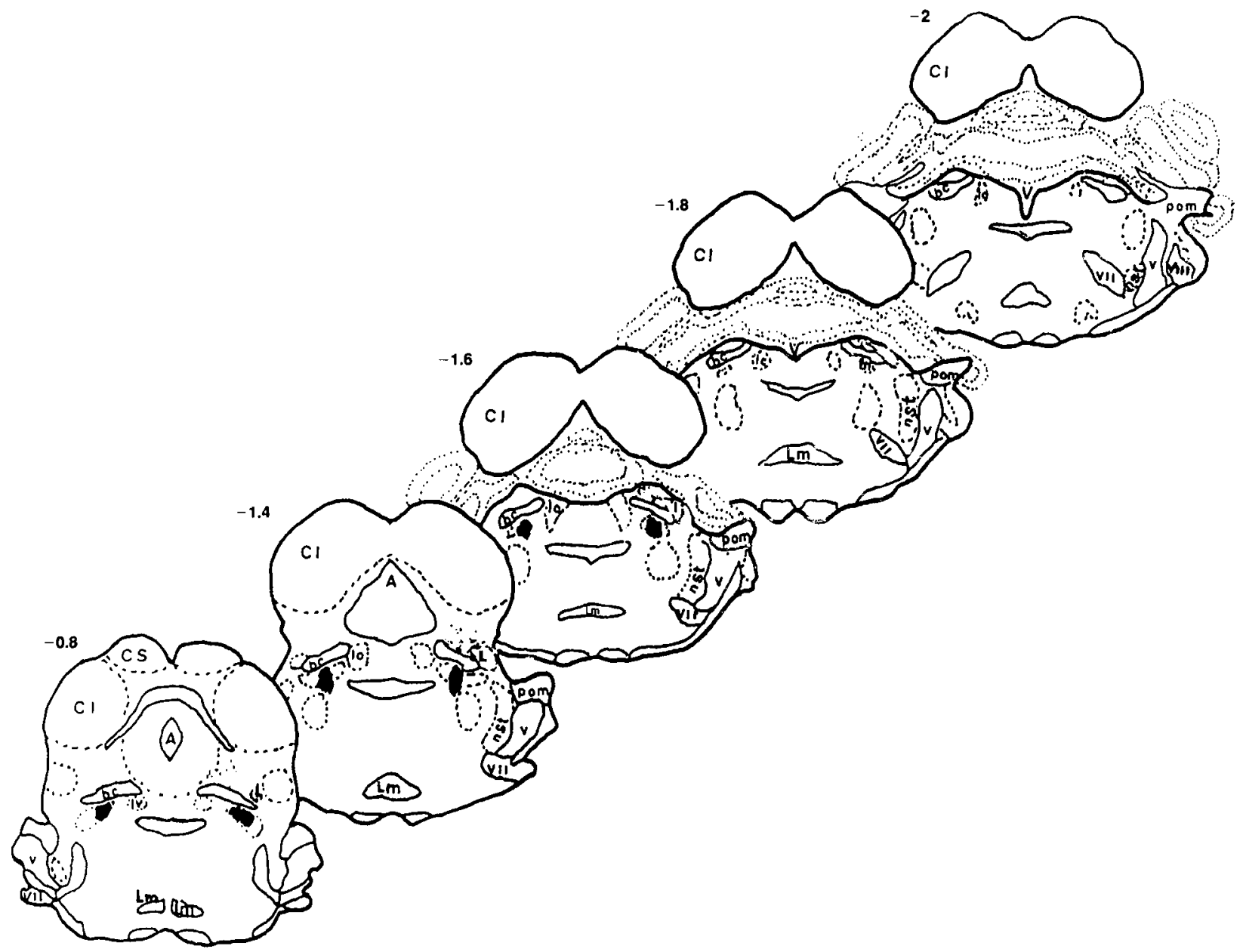

Figure 1. Charting of representative sections that illustrate the relative size of the medial parabrachial nucleus lesions. $A=$ aqueduct; $b c=$ brachium conjunctivum; $\mathbf{C I}=$ inferior colliculus; $\mathbf{C S}=$ superior colliculus; $\mathbf{l c}=$ locus coeruleus; $\mathbf{L m}=$ medial lemniscus; $\mathbf{m}=$ medial parabrachial nucleus; $n s t=$ nucleus of the solitary tract; $\mathbf{p c m}=$ medial cerebellar peduncle; $\mathrm{V}=\mathrm{IV}$ ventricle; $\mathrm{v}=$ nucleus of cranial nerve V; vii $\approx$ nucleus of cranial nerve VII; viii $=$ nucleus of cranial nerve VIII. (Drawing modified from Pellegrino et al., 1979.

ing acquisition trials (i.e., Stimulus $S$ in half of the animals, and Stimulus $\mathrm{C}$ in the other half). This test was intended to determine whether the animals were able to use, in the delayed paradigm, proprioceptive cues (burette position) in association with visceral discomfort caused by the intragastric administration of $\mathrm{LiCl}$. In addition, the test gave us the opportunity to compare consumption of the gustatory stimulus associated with $\mathrm{LiCl}$ (i.e., the only gustatory stimulus available in this test, regardless of whether $\mathrm{S}$ or $\mathrm{C}$ was used) between the lesioned and control groups. In Test 2, given $90 \mathrm{~min}$ later, the subjects had access simultaneously to both stimuli, for $7 \mathrm{~min}$. The position of each stimulus, maintained during the training period, was reversed, so that it could be observed whether or not learning had occurred by gustatory-visceral association.

\section{Results}

Statistical analysis with Student's $t$ test for paired samples revealed no significant differences between the amounts ingested from each burette (regardless of whether $\mathrm{S}$ or $\mathrm{C}$ was used) during the choice test in Test 1 for the experimental group $(t=0.79, p<.4$; see Figure 2a). Mean

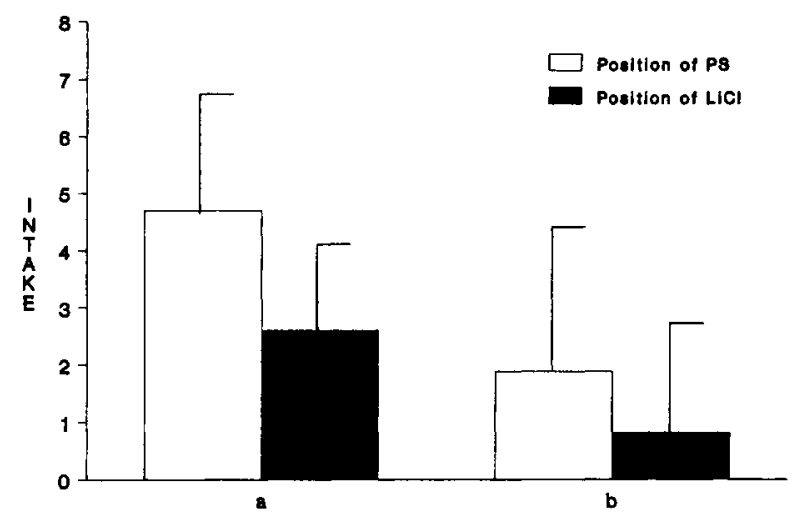

Figure 2. Mean intake $( \pm S D)$ of gustatory stimulus position followed by intragastric administration of $\mathrm{LiCl}$ (filled bars) and neutral gustatory stimulus position (open bars) during the choice test in Test 1 in the experimental group (a) and in the control group (b) of Experiment 1. 
$( \pm S D)$ consumption of the burette placed in the position associated with the intragastric administration of $\mathrm{LiCl}$ and PS was as follows: $\mathrm{LiCL}=2.6 \mathrm{ml}( \pm 1.49)$, and $\mathrm{PS}=$ $4.7 \mathrm{ml}( \pm 1.76)$. In the control group (sham PBNm lesion), no reliable differences were found in Test $1(t=$ $1.96, p<.1$; see Figure $2 b)$. Mean $( \pm S D)$ consumption of the burette placed in the position associated with the intragastric administration of $\mathrm{LiCl}$ and $\mathrm{PS}$ was as follows: $\mathrm{LiCl}=0.82 \mathrm{ml}( \pm 1.89)$, and $\mathrm{PS}=1.88 \mathrm{ml}( \pm 2.62)$. Thus, no position preferences were observed, although there appeared to be a nonsignificant tendency for a visceromotor association to occur.

After analyzing the data with Student's $t$ test for independent samples, significant differences were found between the amount of aversive stimulus drunk by each of the two groups in Test 1 of the choice test $(t=3.65, p<$ .01 ; see Figure 3$)$. Mean ( $\pm S D$ ) consumption of the gustatory stimulus associated with $\mathrm{LiCl}$ ( $\mathrm{S}$ for half the animals, and $\mathrm{C}$ for the other half) in the two groups was as follows: $\mathrm{PBNm}$ group $=7.3 \mathrm{ml}( \pm 1.65)$, and control group $=2.7 \mathrm{ml}( \pm 2.25)$. The PBNm group drank significantly more of the $\mathrm{LiCl}$-associated stimulus than did the control group.

Although some of the control animals drank the stimulus associated with $\mathrm{LiCl}$, the amount ingested was significantly less than that ingested by the experimental animals. This may have been due to the effects of thirst, because of the rigorous deprivation program (drinking water was available for only 7 min each day) and because, at this phase of the study, the animal's only choice was to ingest the gustatory stimulus associated with the toxic substance. Nevertheless, most of the control subjects rejected the situation and refused to drink from either of the burettes.

The animals with PBNm lesions showed no aversion to the gustatory stimulus associated with intragastric administration of $\mathrm{LiCl}$, as shown by the statistical analysis of the Test 2 results in the choice test $(t=0.54, p<.7$; see Figure $4 \mathrm{a})$. Mean $( \pm S D)$ consumption of the gustatory stimulus associated with $\mathrm{LiCl}$ or PS was as follows: $\mathrm{LiCl}=$

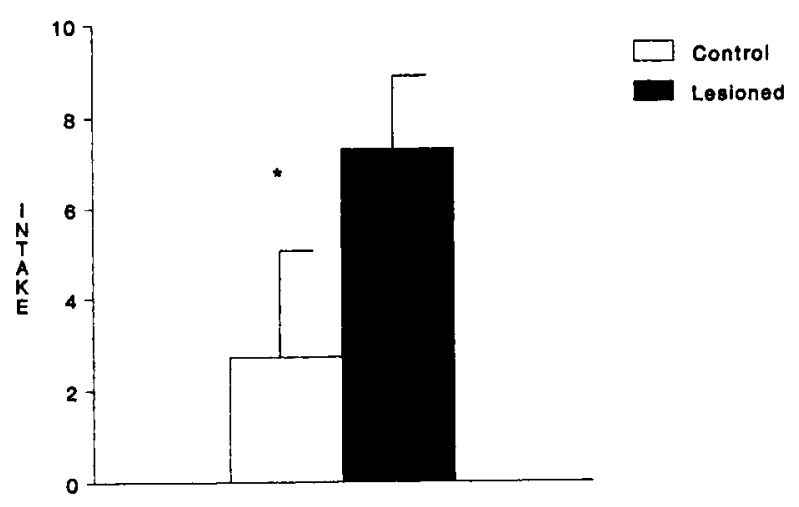

Figure 3. Mean intake $( \pm S D)$ of gustatory stimulus followed by intragastric administration of $\mathrm{LiCl}$ during the choice test in Test 1 in the experimental group (filled bars) and in the control group (open bars) of Experiment 1. ${ }^{*} p<.01$.

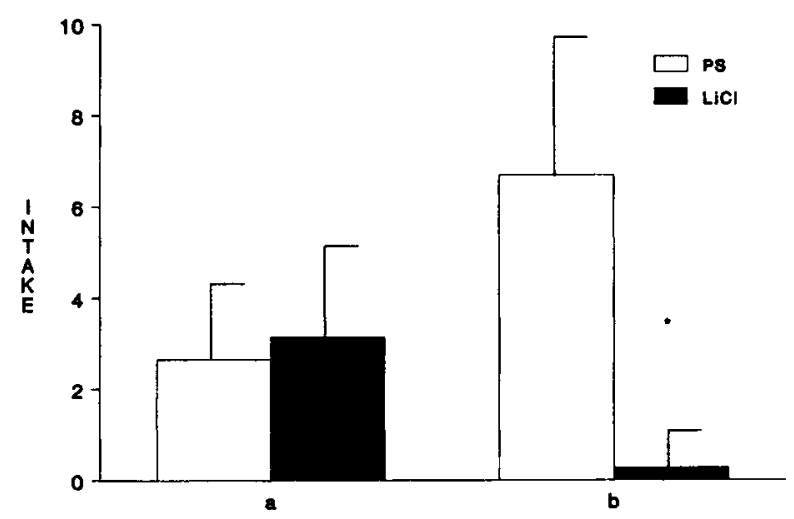

Figure 4. Mean intake $( \pm S D)$ of gustatory stimulus followed by intragastric administration of $\mathrm{LiCl}$ (filled bars) and neutral gustatory stimulus (open bars) during the choice test in Test 2 in the experimental group (a) and in the control group (b) of Experiment $1 .{ }^{*} p<.01$.

$3.14 \mathrm{ml}( \pm 1.95)$, and $\mathrm{PS}=2.65 \mathrm{ml}( \pm 1.52)$. This suggests that learning was disrupted.

In contrast, reliable differences were found in Test 2 of the choice test for the control group $(t=5.48, p<.01$; see Figure $4 \mathrm{~b})$. Mean $( \pm S D)$ consumption of the gustatory stimulus associated with $\mathrm{LiCl}$ or PS was as follows: $\mathrm{LiCl}=$ $0.27 \mathrm{ml}( \pm 0.29)$, and PS $=6.68 \mathrm{ml}( \pm 2.87)$. The subjects consumed significantly more of the gustatory stimulus associated with the administration of isotonic PS, a finding that suggests that these animals acquired learning after only two training trials.

\section{Discussion}

The bilateral lesions to the PBNm prevented learning in a TAL situation. This disability was due exclusively to the lesion, since intact animals subjected to identical experimental procedures learned the task readily.

Lesioned animals, when faced with a typical choice test (Test 2), were unable to learn. These subjects failed to learn with the help of either proprioceptive (position) or exteroceptive cues such as taste or smell. In Test 1, intact animals learned that the gustatory and interoceptive (gastrointestinal discomfort) cues were related and, when faced with the presence of the aversive gustatory stimulus, rejected both burettes. In contrast, the lesioned animals, whose ability to make this connection was incapacitated, consumed the "aversive" gustatory stimulus offered. These results show that PBNm lesions block TAL in a more or less specific manner.

One reasonable explanation of the blockage of TAL by lesions to the PBNm may be rooted in the interruption of the transmission of gustatory information. Many neuroanatomical and electrophysiological reports published to date characterize this subnucleus as an important center for gustatory transmission (Bernard et al., 1993; Block \& Schwartbaum, 1983; Di Lorenzo \& Garcia, 1985; Nishijo \& Norgren, 1991; Norgren, 1976, 1983, 1985; Norgren \& Leonard, 1972). The rats may have been incapable of learning the task because they failed to perceive the gus- 
tatory cues necessary for such learning to occur and failed to detect the gustatory stimuli presented. Taste is a sensorial system that is probably lacking or altered in lesioned rats; thus, these animals were unable to associate the aversive substance with the water that, in Test 2 , lacked a particular flavor that they might have detected. Thus, the blockage observed in PBNm-lesioned animals in a TAL paradigm may be due, at least in part, to a deficit in the processing of gustatory information.

The disruption of TAL by PBNm lesions has been shown in other studies (Di Lorenzo, 1988a; Flynn, Grill, Schulkin, \& Norgren, 1991; Reilly et al., 1993; Spector et al., 1993; Spector et al., 1992; Yamamoto \& Fujimoto, 1991). The blockage of learning observed by other authors was interpreted as an alteration in the gustatory system (Yamamoto \& Fujimoto, 1991; Yamamoto, Shimura, Sako, Yasohima, \& Sakai, 1994) or as an associative deficit (Flynn, Grill, Schulkin, \& Norgren, 1991; Reilly et al., 1993; Spector et al., 1993; Spector et al., 1992).

\section{EXPERIMENT 2}

The results of Experiment 1 show that lesioning the PBNm disrupted the animals' capacity to acquire taste aversion in a delayed learning paradigm. As noted above, the deficit induced by the lesion may be gustatory; however, other possibilities cannot be ruled out.

If the deficit caused by lesioning the PBNm is mainly gustatory in nature, the subjects would be able to acquire this task if other alternative sensory cues were available (i.e., proprioceptive, olfactory, and so on). Olfaction seems to be an important and well-studied component of TAL, and it has many features in common with gustatory cues, with which it is frequently associated (FernandezRuiz et al., 1993; Garcia \& Rusiniak, 1980; Hankins, Garcia, \& Rusiniak, 1973; Reilly et al., 1993; Rusiniak, Garcia, Palmerino, \& Cabral, 1983; Rusiniak, Hawkins, Garcia, \& Brett, 1979; Staubli, Schottler, \& Nejat-Bina, 1987). However, in functional terms, the olfactory system is, in many ways, more like the visual or auditory system in terms of the establishment of olfactory-visceral associations (Garcia \& Brett, 1977; Van Buskirk, 1981). Thus, a visceral-olfactory association (as well as, e.g., a proprioceptive-visceral or a visual-visceral association) will not form unless the delay between the olfactory stimulus and internal discomfort is shorter than a few minutes or seconds (Coburn, Garcia, \& Kiefer, 1984; Palmerino, Rusiniak, \& Garcia, 1980; Panhuber, 1982; Rusiniak et al., 1979). On the basis of this information, Experiment 2 was designed to allow the animals to make use of the olfactory cues (among other exteroceptive or proprioceptive cues) associated with the beverage, followed immediately by the intragastric administration of $\mathrm{LiCl}$ or PS.

\section{Method}

Subjects. The subjects were 16 male Wistar rats weighing $250-320 \mathrm{~g}$. They were maintained under the same conditions as noted in Experiment 1.
Surgery. The surgical intervention was the same as in Experiment 1 .

Behavioral procedure. After surgery, 1 week was aliowed for postoperative recovery. After this period, the animals were given 5 days of training. The rats were placed on a 23-h 53-min waterdeprivation schedule and allowed to drink tap water for 7 min only from two graduated burettes presented simultaneously. The experimental sessions did not begin until all animals had learned to drink alternately from the two burettes to avoid the development of positional preferences. During this period, the animals learned to drink continuously, alternating between the two burettes. If drinking did not recommence within $30 \mathrm{sec}$, both burettes were immediately removed. This restricted drinking procedure was used because the main cues available to the animals during the acquisition process are either exteroceptive (olfactory cues or visual cues-i.e., colorassociated with the gustatory stimuli presented) or proprioceptive (based on the position of the burettes), and it has been shown that these cues become associated only in nondelay situations (Coburn et al., 1984; Di Lorenzo, 1988a; Doty, Gregor, \& Settle, 1986; Grigson et al., 1994; Palmerino et al., 1980; Panhuber, 1982).

As during the adaptation period, the experimental sessions lasted $7 \mathrm{~min}$. After 5 days of training, the experimental phase was begun according to the procedure shown in Experiment l, the only variation being the lack of delay between presentation of the stimuli and the intragastric administration of the toxic and nontoxic substance. There was one daily session during 4 days, with the same stimuli as in Experiment 1. Two different stimuli were available on alternate days: strawberry (S) and coconut (C) extracts. In each of the training sessions, the subjects had access to one of the stimuli for $7 \mathrm{~min}$ Only one of the stimuli (appropriately balanced) was followed by the intragastric administration of $0.15 \mathrm{M} \mathrm{LiCl}$ immediately thereafter. The same procedure was used in sessions in which the animals were given the neutral stimulus, except that PS was injected. Half of the animals received $\mathrm{LiCl}$ immediately after drinking S; the other half received $\mathrm{LiCl}$ after drinking $\mathrm{C}$. The sequence of the sessions and position of the burette were suitably balanced.

After two trials (four sessions), the choice test was presented in two phases, using the same procedure as in Experiment 1. The phases were separated by a 90-min interval. As in Experiment 1, Test 1 showed whether association had occurred preferentially with the position of the stimulus during the learning process, because only the gustatory stimulus associated with $\mathrm{LiCl}$ during the training phase was available. The choice (if learning had occurred) could only have been made on the basis of proprioceptive cues (position). If learning occurs on the basis of a proprioceptive-visceral association, the animals will choose to drink from the burette in the position associated with PS administration, because the stimulus presented (in both burettes) is always associated with the intragastric administration of $\mathrm{LiCl}$. Test 2 revealed not only whether learning had occurred but also whether the sensory cues used were proprioceptive (position) or other nongustatory stimuli (olfaction, color, etc.), given that the gustatory component of stimulus was not used by the lesioned animals in Experiment 1.

\section{Results}

Statistical analysis with Student's $t$ test for paired samples revealed no significant differences between the amounts ingested from each burette during the choice test in Test 1 for the experimental group $[t=0.69, p<.6$; mean $( \pm S D)$ consumption of the burette placed in the position associated with the intragastric administration of $\mathrm{LiCl}$ and $\mathrm{PS}$ was $\mathrm{LiCl}=1.93 \mathrm{ml}( \pm 2.11)$, and $\mathrm{PS}=$ $2.95 \mathrm{ml}( \pm 3.56)]$ or for the control group $[t=2.17, p<$ .1 ; mean $( \pm S D)$ consumption of the burette placed in the position associated with the intragastric administration of $\mathrm{LiCl}$ and $\mathrm{PS}$ was $\mathrm{LiCl}=0.63 \mathrm{ml}( \pm 0.65)$, and $\mathrm{PS}=$ 


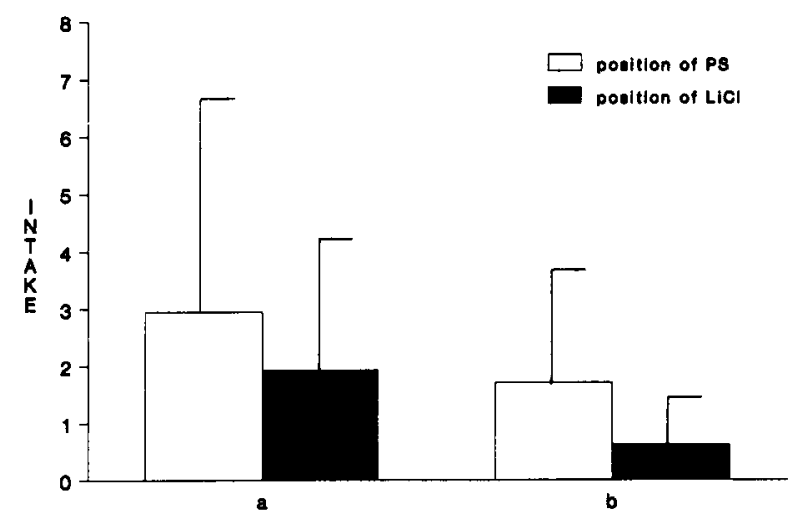

Figure 5. Mean intake $( \pm S D)$ of gustatory stimulus position followed by intragastric administration of $\mathrm{LiCl}$ (filled bars) and neutral gustatory stimulus position (open bars) during the choice test in Test 1 in the experimental group (a) and in the control group (b) of Experiment 2.

$1.7 \mathrm{ml}( \pm 1.9)$ ] (see Figure 5). Thus, no positional effects were observed. By contrast, the rats learned to discriminate well between the two chemical agents on the basis of olfactory indicators (or any other indicator that may be associated with the gustatory stimuli presented), as shown by the significant differences obtained in Test 2 of the choice test for the experimental group $[t=4.7, p<$ .001 ; mean $( \pm S D)$ consumption of the gustatory stimulus associated with $\mathrm{LiCl}$ or PS was $\mathrm{LiCl}=1.12 \mathrm{ml}( \pm 1.06)$, and PS $=4.83 \mathrm{ml}( \pm 2.37)]$ and the control group $[t=$ $6.87, p<.001$; mean $( \pm S D)$ consumption of the gustatory stimulus associated with $\mathrm{LiCl}$ or $\mathrm{PS}$ was $\mathrm{LiCl}=0.25 \mathrm{ml}$ $( \pm 0.7)$ and $\mathrm{PS}=9.32 \mathrm{ml}( \pm 3.41)]$ (see Figure 6).

\section{Discussion}

The ease with which PBNm-lesioned animals acquired learning in a long-term nondelayed TAL task contrasts with the results of Experiment 1. The only change introduced in Experiment 2 was the removal of the delay between the presentation of the stimuli and the administration of the toxic substance. This small modification allowed the animals to use other (exteroceptive and proprioceptive) sensory cues that were unavailable to the animals in the paradigm used for Experiment 1.

That learning took place with the help of exteroceptive (olfactory, visual, etc.) cues is evidence that, although the PBNm receives olfactory information (Di Lorenzo \& Garcia, 1985), this nucleus is not essential for these cues to be used as discriminative stimuli that indicate a certain visceral state, as was the case in the TAL paradigm.

These findings may be explained on the basis of the design of Experiment 1, which was intended to reduce the participation of other sensory systems by introducing a 15-min delay between the presentation of the gustatory stimulus and injection of the toxic $(\mathrm{LiCl})$ or nontoxic (PS) substance into the stomach. This period appears to be long enough to prevent potential associations with other sensory systems, such as the proprioceptive system (motor response required for a certain position), olfac- tory cues, or any other cues that may be associated to the gustatory stimuli presented.

With regard to olfactory sensory cues, experimental studies have shown that olfactory-visceral associations are established with relative ease (Bouton \& Whiting, 1982; Fernandez-Ruiz et al., 1993; Garcia \& Rusiniak, 1980; Palmerino et al., 1980; Panhuber, 1982; Reilly et al., 1993; Van Buskirk, 1981). However, such associations are possible only when the interval between presentation of the olfactory cue and administration of the toxic substance is brief, as shown in earlier studies (Garcia \& Brett, 1977; Rusiniak et al., 1983; Schneider \& Whote, 1979) and as suggested in the experiment above. These cues (proprioceptive, olfactory information, color, etc.) are not utilizable when learning is delayed. The gustatory component is likely to be the determining factor in delayed learning; without it, the other sensory cues are ineffective and insufficient. If the animals in Experiment 2 did not learn on the basis of proprioceptive cues, as shown by the results of Tests 1 and 2, they must have used other cues. The same stimuli were used in Experiments 1 and 2 ; however, the animals were able to use them only when there was no delay. If these cues could not be used under delayed conditions (Experiment 1), it was because some of the characteristics of these stimuli require contiguity for learning to occur. In summary, the removal of delay favors the use of some of the features of these stimuli (including, perhaps, their olfactory component; see Palmerino et al., 1980) for the association with the administration of $\mathrm{LiCl}$, the visceral agent. Moreover, it may be that the immediate procedure allowed the weakened sensory trace to become associated with the visceral event, whereas the delayed procedure, perhaps because the weak trace had decayed, did not.

These observations show that the PBNm is not essential in intragastric $\mathrm{LiCl}$ sensory processing, as can be deduced from the fact that these animals were able to learn in nondelayed TAL tasks. They were able to establish an

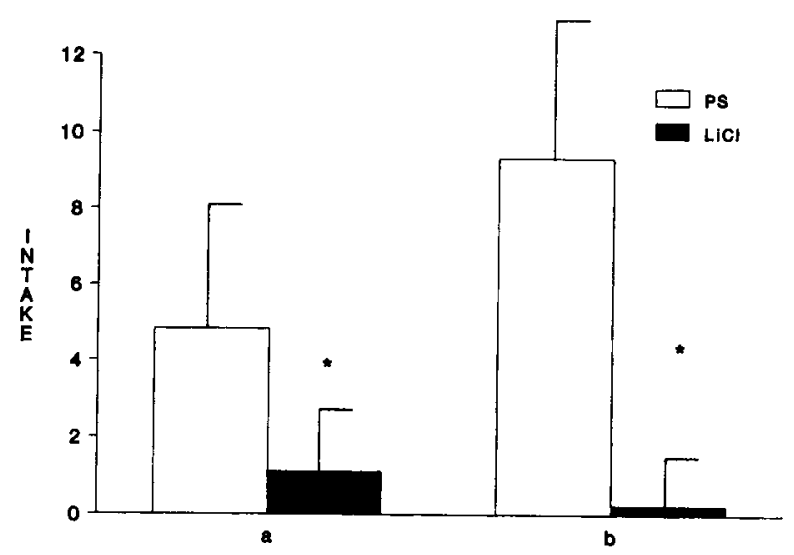

Figure 6. Mean intake $( \pm S D)$ of gustatory stimulus followed by intragastric administration of $\mathrm{LiCl}$ (filled bars) and neutral gustatory stimulus (open bars) during the choice test in Test 2 in the experimental group (a) and in the control group (b) of Experiment $2 .{ }^{*} p<.001$. 
association between external cues and the intragastric administration of $\mathrm{LiCl}$. If the lesion caused an essential deficit in $\mathrm{LiCl}$ processing, these animals would not be able to establish the association, since one of the components (visceral) of the learning paradigm would have been obviated. In contrast, if the animals subjected to a nondelayed TAL task learned, this was because some of the main sensory components involved in learning had not been eliminated. An associative impairment is also unlikely, since learning did, in fact, occur.

\section{EXPERIMENT 3}

The results of Experiment 2 show that animals with electrolytic lesions of the PBNm were able to learn a TAL task when they were provided, in a delayless TAL paradigm, with sensory (i.e., olfactory among them) cues that allowed them to learn the required association. This was not the case in Experiment 1 (despite the ease with which the intact animals learned the task), in which the only change introduced was the 15 -min delay between the gustatory stimulus and the visceral stimulus.

These findings suggest that the disruption of TAL probably occurs as a result of a deficit in the processing of gustatory information, although other alternatives may be proposed: (1) a deficit in visceral processing of $\mathrm{LiCl},(2)$ an associative deficit, and (3) a memory deficit. However, in PBNm-lesioned animals, the visceral processing of $\mathrm{LiCl}$ appeared to be unaffected - the animals readily learned TAL tasks in which the external and visceral stimuli were presented without interstimulus delay (Experiment 2). Similarly, no associative impairment can be involved because the animals were able to learn some of the tasks. However, recently, other authors have cited this as the most likely explanation (e.g., Flynn, Grill, Schulkin, \& Norgren, 1991 b; Reilly et al., 1993; Spector et al., 1993; Spector et al., 1992). With regard to the memory deficit, this possibility cannot be ruled out on the basis of currently available data (Experiment 2), although other authors (Schafe, Seeley, \& Bernstein, 1995; Yamamoto et al., 1994) and subsequent findings in this series of experiments failed to support this hypothesis.

On the basis of these observations, Experiment 3 was designed to test whether the gustatory deficit attributed to the PBNm lesion in TAL tasks could be demonstrated directly in habitual taste discrimination paradigms (Benjamin, 1955; Braun, Lasiter, \& Kiefer, 1982; Pfaffman, 1952). The available neuroanatomical evidence (Beckstead, Morse, \& Norgren, 1980; Nomura \& Ogawa, 1985; Norgren, 1976, 1985; Norgren \& Leonard, 1972) would appear to support this hypothesis, since, as previously mentioned, the PBNm is the second relay in the transmission of this information toward rostral structures of the CNS. If this is so, and if the PBNm is a fundamentally gustatory nucleus, then lesioned animals presented with a discrimination task based on different stimuli (in this case, saccharine and quinine) at different (discriminated) concen- trations should show specific differences in comparison with intact control animals faced with the same task.

\section{Method}

Subjects. The subjects were 17 male Wistar rats weighing $280-$ $320 \mathrm{~g}$. They were maintained under the same conditions as noted in Experiment 1. Eight animals were assigned to the control group (sham lesion), and the remaining 9 were assigned to the experimental group (electrolytic lesion of the PBNm).

Surgery. The surgical intervention was the same as in Experiment 1 .

At the conclusion of the experiment, the subjects were then perfused intracardially, and the brains were removed and stored in $10 \%$ formaldehyde for a minimum of $48 \mathrm{~h}$. Electrolytic lesions were located in slides prepared with a freezing microtome and were studied under a light microscope. Detailed descriptions of the measurements and extension of the lesions were given in Experiment 1.

The histological data are not shown because no significant differences were seen with regard to previous experiments.

Behavioral procedure. After the animals had recovered from surgery, they were allowed to adapt to the drinking schedule that was to be in effect for the remainder of the experimental procedure. Water was available during $1 \mathrm{~h}$ each day from a graduated burette, the location of which was varied to avoid the development of positional preferences. Throughout the habituation and experimental periods, $20 \mathrm{~g}$ of rat chow (Sanders compound chow, Unidad Alimentaria Sanders, Granada, Spain) was available each day. After a 5-day adaptation period, during which only water was available, the gustatory discrimination test was begun. The gustatory stimuli were sodium saccharine (Sucesores de José Escuder, Barcelona) and quinine hydrochloride (Sigma, St. Louis), the most widely used substances in this type of study (Benjamin, 1955; Braun et al., 1982; Frank \& Nowlis, 1989; Herness \& Pfaffman, 1986; Hill \& Almli, 1983; Jacquin, 1983; Kiefer \& Lawrence, 1988; Pfaffman, 1952; St. John, Garcea, \& Spector, 1994). Four concentrations of each stimulus were prepared, ranging in strength from weak to highly aversive. The choice of these concentrations was based on a pilot study with intact animals not subjected to surgery. After different concentrations were tested (but not used in this experiment), we decided to consider the "threshold" value of saccharine as that concentration at which the rats consumed significantly more gustatory stimulus than water. The threshold value of quinine was considered that concentration at which the animals rejected significantly more gustatory stimulus than water. For quinine $(\mathrm{Q})$, the concentrations were (1) $0.0004 \%$, (2) $0.001 \%$, (3) $0.005 \%$, and (4) $0.01 \%$; for saccharine $\left(\mathrm{S}_{\mathrm{a}}\right)$, the concentrations were (1) $0.030 \%$, , (2) $0.2 \%$, , (3) $1 \%$, and (4) $2 \%$. The gustatory stimuli (each concentration) were presented twice to each animal, and the presentation of a given flavor was alternated with the presentation of water. That is, for $1 \mathrm{~h}$ each day, one gustatory stimulus (each concentration or tap water) was available on alternate days. The position of the burette was also varied daily. The stimuli were presented in increasing or decreasing order of concentration; thus, all variables (order of presentation and position) were balanced.

\section{Results}

Student's $t$ test for paired samples was used to compare the intake of different concentrations of each gustatory stimulus by each group with water intake on the days before and after the first presentation of the gustatory stimulus or with the water consumed on the days before and after the second presentation of the gustatory stimulus, according to the balancing procedure. Student's $t$ test for paired samples was also used to compare the amounts of 
$\mathrm{Q}$ and $\mathrm{S}_{\mathrm{a}}$ consumed. To compare the results in the experimental and control groups, Student's $t$ tests for independent samples and analysis of variance (ANOVA) for repeated samples were used.

The amount of the lowest concentration of Q consumed was similar to the amount of water consumed in the animals in the lesioned and sham-lesioned groups (control, $t=0.35, p<.8$; experimental, $t=1, p<.4$ ).

The second concentration of $Q$ was rejected by control animals at a significant rate relative to water intake $(t=$ $2.43, p<.05)$. In contrast, experimental animals showed no sign of having discriminated the stimulus $(t=1.16$, $p<.3$ ), with no significant difference between the amounts of stimulus and water consumed (Figures 7 and 8 ).

Statistical analysis of the results obtained with saccharine showed that the PBNm-lesioned subjects were very sensitive to this substance, which they were able to dis-

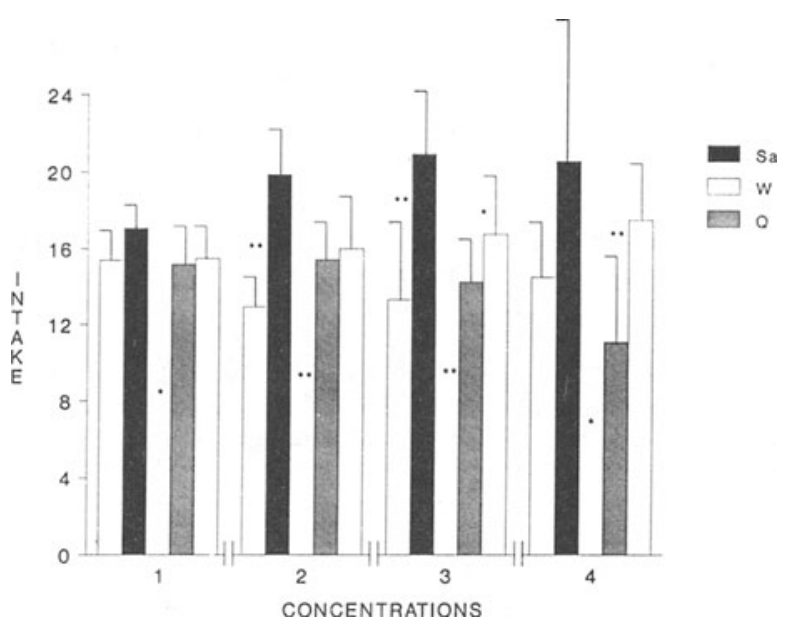

Figure 7. Mean intake $( \pm S D)$ of the different gustatory stimuli used in the taste discrimination test in the experimental group of Experiment 3. $S_{\mathbf{a}}=$ saccharine; $Q=$ quinine; $W=$ plain water. ${ }^{*} p<.05 . \quad{ }^{* *} p<.001$.

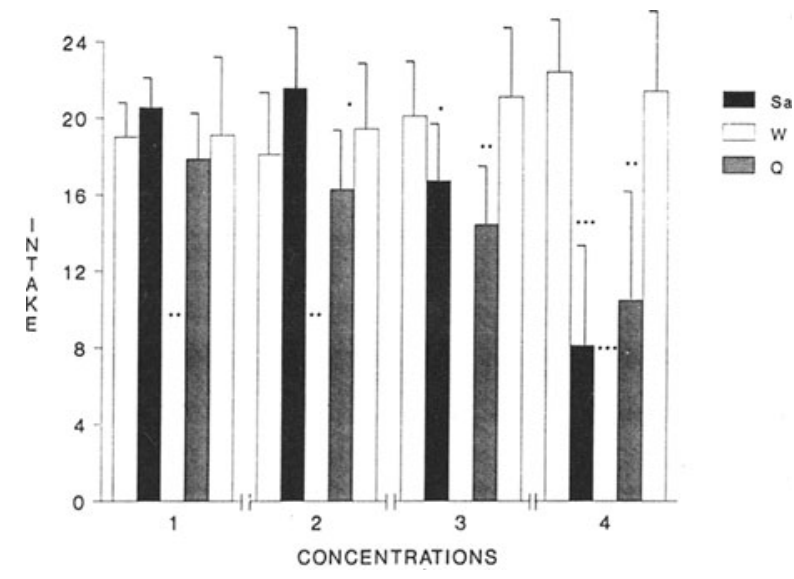

Figure 8. Mean intake $( \pm S D)$ of the different gustatory stimuli used in the taste discrimination test in the control group of Experiment 3 . $S_{\mathrm{a}}=$ saccharine; $Q=$ quinine; $W=$ plain water. ${ }^{*} p<.05 . \quad{ }^{* *} p<.01 . \quad{ }^{* * *} p<.001$. criminate at the second lowest concentration tested. The animals drank significantly more $\mathrm{S}_{\mathrm{a}}$ solution than water $(t=15.7, p<.001)$. Although the control subjects also consumed more $\mathrm{S}_{\mathrm{a}}$ solution than water, this difference failed to reach significance $(t=2.26, p<.1)$. The most obvious differences in behavior between the two groups appeared when the two higher concentrations were offered $\left(\mathrm{S}_{\mathrm{a} 3}\right.$ and $\left.\mathrm{S}_{\mathrm{a} 4}\right)$. While control animals showed some aversion to the third concentration $(t=2.36, p<.05)$, PBNm-lesioned animals showed a significant preference for this solution over water $(t=5.68, p<.001)$. The highest concentration of $\mathrm{S}_{\mathrm{a}}$ was aversive to control subjects, which clearly preferred water $(t=5.79, p<.001)$. In contrast, lesioned animals drank more of the highest concentration of $\mathrm{S}_{\mathrm{a}}$ than water, although this difference failed to reach statistical significance $(t=2.14, p<.1)$. In other words, intact subjects began to reduce their $S_{a}$ intake at the third and fourth concentrations. Lesioned animals also showed "peak" preference for the second and third concentrations (the third was rejected, to some extent, by controls) over the first but showed no signs of rejecting the third or fourth concentrations, which were highly aversive to control animals (Figures 7 and 8). When we compared $Q$ intakes, expressed as a percentage of total consumption (gustatory stimulus $\times 100$ )/(gustatory stimulus + water) for the two groups, we found that experimental animals drank more of all concentrations of the stimulus than did controls, although the difference was not significant for any concentration (Concentration $1, t=0.53$, $p<.6$; Concentration 2, $t=1.76, p<.1$; Concentration 3, $t=1.18, p<.1$; Concentration $4, t=1.19, p<.2)$. ANOVA confirmed the absence of significant differences between the two groups $[F(1,16)=2.85, p<.2]$ (see Figure 9).

However, $\mathrm{S}_{\mathrm{a}}$ intake in the two groups differed significantly for the second, third, and fourth concentrations, which were consumed in greater amounts by lesioned animals than by controls (Concentration $2, t=3.18, p<.01$; Concentration 3, $t=13.23, p<.001$; Concentration 4, $t=$ $4.64, p<.001)$. ANOVA confirmed the difference in $\mathrm{S}_{\mathrm{a}}$ intake (expressed as a percentage of total consumption, as noted above) between the two groups $[F(1,16)=35.7$, $p<.001$ ] (see Figure 9).

\section{Discussion}

The results of Experiment 3 show that lesioning the PBNm alters the discrimination of taste qualities. These findings are compatible with the observations in an extensive body of neuroanatomical and electrophysiological research (Bernard et al., 1993; Di Lorenzo \& Schwartzbaum, 1982a, 1982b; Hayama \& Ogawa, 1987; Nishijo \& Norgren, 1991; Ogawa, Hayama, \& Ito, 1984; Ogawa, Imoto, \& Hayama, 1984; Perroto \& Scott, 1976; Saper \& Loewy, 1980; Schwartzbaum, 1983; S. P. Travers \& Smith, 1984; Yamada et al., 1990) and provide an additional behavioral dimension. Moreover, they are consonant with recently published behavioral studies (Flynn, Grill, Schwartz, \& Norgren, 1991; St. John et al., 1994). The aforementioned studies have identified this subnucleus of the parabrachial complex as an area of the pons 




Figure 9. Percent of mean intake $( \pm S D$ ) of each gustatory stimulus in comparison with water at each of the concentrations of $S_{\text {a }}$ (saccharine) and $Q$ (quinine) for each of the groups (experimental and control) in the first part of Experiment 3. Percent of intake $=$ gustatory stimulus divided by total intake (gustatory stimulus + plain water) $\times 100 . \quad{ }^{*} p<.001$.

where gustatory information is processed. This area represents the second relay in the transmission of gustatory information toward more rostral levels of the CNS-for example, the thalamus (Lasiter \& Glanzman, 1983), amygdala (Bernard et al., 1993; Block \& Estes, 1990; Block, Hoffman, \& Kapp, 1989; Block \& Schwartbaum, 1983; Fernandez-Ruiz et al., 1993; Moga \& Gray, 1985a, 1985b; Moga, Saper, \& Gray, 1989; Schwaber, Sternini, Brechna, Rogers, \& Card, 1988; Takeuchi, McLean, \& Hopkins, 1982; Takeuchi, Takahashi, Satoda, \& Matsuchima, 1987), hypothalamus (Aas \& Brodal, 1988, Ferssiwi, Cardo, \& Velley, 1987), and cortex (Di Lorenzo, 1990; Lasiter et al., 1982; Saper, 1982; Shipley \& Sanders, 1982; Yasui et al., 1985). Most research has centered on these rostral areas of projection, although various studies have suggested that the main substrate for the discrimination of taste qualities (sweet, salty, bitter, and sour) may be located in more caudal structures, such as the pontine PBN (Braun et al., 1982; Scott \& Perroto, 1980; Smith, Van Buskirk, Travers, \& Bieber, 1983a, 1983b).

The deficit observed in Experiment 3 was only partial: Lesioned subjects conserved gustatory sensitivity and discriminated the gustatory stimuli presented, although both of these capacities were altered. The PBNmlesioned animals distinguished the appetitive nature of $\mathrm{S}_{\mathrm{a}}$, as shown by the greater consumption of this stimulus than of water. In contrast, control subjects consumed more of the weaker stimulus than water but, nonetheless, distinguished the qualitative change in the stimulus. As the concentration of $\mathrm{S}_{\mathrm{a}}$ increases, it ceases to be appetizing (sweet) and becomes an aversive (bitter) stimulus, similar to Q (Miller \& Teates, 1986; Wong, 1985). The preference for this substance changed significantly with the third highest concentration, which was rejected and consumed less than water. Control subjects drank similar amounts of the third and fourth $Q$ and $S_{a}$ concentrations, whereas lesioned animals continued to prefer the third and fourth highest concentrations of $S_{a}$, which they distinguished as different from $Q$. These results are consistent with earlier studies in several-day-old PBNmlesioned rat pups (Hill \& Almli, 1983) and with the findings obtained after the gustatory cortex was ablated (Braun et al., 1982; Kiefer, 1985; Kiefer \& Braun, 1979; Kiefer, Leach, \& Braun, 1984a, 1984b; Kiefer, Rusiniak, \& Garcia, 1982; Yamamoto, Matsuo, \& Kawamura, 1980). As in these studies, our lesioned rats were extremely sensitive to $S_{a}$. The deficit we observed seems to specifically affect the aversion for this gustatory stimulus-that is, the point at which the gustatory stimulus is rejected and at which the amount of stimulus ingested becomes significantly lower than the amount of water consumed. The change from "preferred" to "aversive" in intact rats was at the third concentration, whereas this change began to be manifested in lesioned rats at the fourth (highest) concentration, although this group continued to prefer the $\mathrm{S}_{\mathrm{a}}$ solution to water. This means that even higher concentrations of $\mathrm{S}_{\mathrm{a}}$ would need to be presented before PBNmlesioned animals would begin to significantly reduce their intake of this substance. The results obtained with $Q$ are also compatible with the findings in a number of electrophysiological studies (Di Lorenzo \& Schwartzbaum, 1982a, 1982b; Nishijo \& Norgren, 1991; Schwartzbaum, 1983; Smith et al., 1983a, 1983b; S. P. Travers \& Smith, 1984; Yamada et al., 1990) and behavioral studies (Flynn, Grill, Schwartz, \& Norgren, 1991; Hill \& Almli, 1983; Jacquin, 1983). Rats with PBNm lesions rejected $Q$ and drank more water, although these differences were significant only at the two higher concentrations. In contrast, rejection by control animals appeared at the second concentration of this substance. These findings appear to support a deficit in Q discrimination: Although PBNmlesioned animals distinguished the "aversiveness" of this stimulus, they required a higher concentration than to reject it in favor of water than did control animals.

One possible explanation for the slight differences in $Q$ consumption between the experimental and control groups is that this information may be processed at more caudal levels of the brain stem, possibly in the nucleus of the solitary tract (Di Lorenzo \& Schwartzbaum, 1982a, 1982b; S. P. Travers, Pfaffman, \& Norgren, 1986) or that the lesion to the PBNm used in the present series of experiments may not have completely destroyed all of the Q-specific cells. Moreover, electrophysiological studies of the PBN indicate that the number of Q-sensitive fibers at this level of the pons is very limited (Nishijo \& Norgren, 1991; Ogawa, Hayama, \& Ito, 1987; Scott \& Perroto, 1980; S. P. Travers \& Smith, 1984; Yamada et al., 1990), suggesting that this information may be processed, to some extent, in first- and second-order neurons of the gustatory system (St. John et al., 1994). According to other findings, $Q$ may be an aversive discriminative stimulus in 12-day-old rats (Hill \& Almi, 1983; Johanson \& Shapiro, 1986; Shapiro \& Johanson, 1985). Taken together, these observations may indicate that very primitive systems, possibly situated at the first level of information processing, may be prepared to distinguish the hedonic characteristics of the innately "negative" stimu- 
lus, without the need to resort to higher levels (PBN). The functions of these higher centers may be limited to a finer level of discrimination and perception. On the other hand, it is also possible that experience with this gustatory stimulus throughout the experiment contributed to a functional recovery of "gustatory reactivity" after the lesion (Pritchard, Reilly, Hamilton, \& Norgren, 1994). Similarly, given the characteristics of the present experiment, acceptance or rejection of the different concentrations of the stimuli may have been influenced not only by oral or gustatory factors but also by postingestional factors (Contreras \& Smith, 1990; Flynn, Grill, Schwartz, \& Norgren, 1991 ), since the stimulus was available to the subjects for $1 \mathrm{~h}$ a day. These postingestional factors may have caused $Q$ to be rejected by lesioned animals despite their deficit in gustatory discrimination.

\section{EXPERIMENT 4}

The results of Experiment 3 show that lesioning the PBNm impaired the animal's gustatory capacity. These findings are compatible with earlier anatomical and electrophysiological observations (Di Lorenzo \& Schwartzbaum, 1982a, 1982b; Norgren \& Leonard, 1972; Schwartzbaum, 1983; Smith et al., 1983a, 1983b; S. P. Travers \& Smith, 1984; Yamada et al., 1990).

However, the results of this experiment suggest that certain concentrations of $Q$ and $S_{a}$ may be discriminated by PBNm-lesioned animals. On the basis of these observations, delayed TAL may occur when the animal uses these stimuli and concentrations. Experiment 4 was designed to test this hypothesis.

Although $\mathrm{S}_{\mathrm{a}}$ is frequently used in studies of TAL (Benjamin, 1955; Braun et al., 1982; Frank \& Nowlis, 1989; Herness \& Pfaffman, 1986; Hill \& Almli, 1983; Jacquin, 1983; Kiefer \& Lawrence, 1988; Pfaffman, 1952), Q is rarely used as a gustatory stimulus, because of its aversive quality. This characteristic was controlled for by suitably balancing the experimental protocol.

\section{Method}

Subjects. The subjects were 24 male Wistar rats weighing 280 $330 \mathrm{~g}$. They were maintained under the same conditions as described in the previous experiments.

Surgery. Surgical and histological procedures were performed as described previously.

Behavioral procedure. The general procedure was as described in Experiment 1, except that the gustatory stimuli $\mathrm{S}$ and $\mathrm{C}$ were replaced with other gustatory stimuli that were distinguished as different stimuli by the experimental animals $\left(\mathrm{S}_{\mathrm{a}_{2}}\right.$ and $\left.\mathrm{Q}_{3}\right)$. During the adaptation period, the animals had access to two graduated burettes (containing tap water) for $7 \mathrm{~min}$. The burettes were presented simultaneously to avoid the development of positional preferences. After 5 days of adaptation, the experimental sessions were begun. In each of the training sessions, the subjects had access to one of the stimuli for $7 \mathrm{~min}$. In sessions in which the animals were given the aversive stimulus after a 15-min delay, ingestion was followed by the intragastric administration $(50 \%$ of the amount of stimulus ingested) of $0.15 \mathrm{M} \mathrm{LiCl}$.

The same procedure was used in sessions in which the animals were given the neutral stimulus, except that PS was administered. One session per day was carried out at approximately the same time of day. Hence, two acquisition trials alternated with neutral trials. The order of presentation, spout position, and stimulus followed by $\mathrm{LiCl}$ were suitably balanced.

After all variables had been balanced, two experimental groups were established. The rats in $\mathrm{Group}$ a received $\mathrm{LiCl}$ intragastrically 15 min after drinking Stimulus Q; the rats in Group $b$ received $\mathrm{LiCl}$ after drinking Stimulus $\mathrm{S}_{\mathrm{a}}$. Half of the animals belonged to the control group; the other half belonged to the PBNm-lesioned group.

After two trials, the choice test was presented in two phases. In both groups, Test 1 consisted of the simultaneous presentation of two burettes containing the same stimulus for $7 \mathrm{~min}$. Group A (which consisted of half of the animals from each of Groups a and b) had access to the stimulus associated with $\mathrm{LiCl}$; Group B (the other half of the animals from Groups a and b) had access to the neutral stimulus $\left(\mathrm{S}_{\mathrm{a}}\right.$ or $\left.\mathrm{Q}\right)$. The test was used to determine whether a single-stimulus test under extreme deprivation conditions can detect differences, when learning has occurred, between consumption of the aversive stimulus (associated with intragastric administration of $\mathrm{LiCl}$ during conditioning) and the neutral stimulus (associated with PS). This single-stimulus test predicted opposite behaviors in the two groups. If learned aversion occurred, Group A would consume smaller quantities of stimulus than would Group B. In Test 2, presented $90 \mathrm{~min}$ later, the subjects had access simultaneously to both stimuli, $\mathrm{S}_{\mathrm{a}}$ and $\mathrm{Q}$, for $7 \mathrm{~min}$. The position of each stimulus, maintained during the training period, was reversed, so that it could be observed whether or not learning occurred by gustatory-visceral association.

\section{Results}

The data for 1 of the experimental subjects, which died before the end of the test, were not included in the statistical analysis. Student's $t$ test for paired samples was used to compare intake of each of the gustatory stimuli in the second phase (Test 2) of the choice test. To compare the data from subgroups of animals presented with a different gustatory stimulus in the first phase (Test 1 ) of the choice test, Student's $t$ test for independent samples was used.

Mean intake in the subgroup presented with the aversive ( $\mathrm{LiCl}$-associated) stimulus in the first phase of the choice test was significantly lower than in the subgroup given the positive (PS-associated) stimulus for both ex-

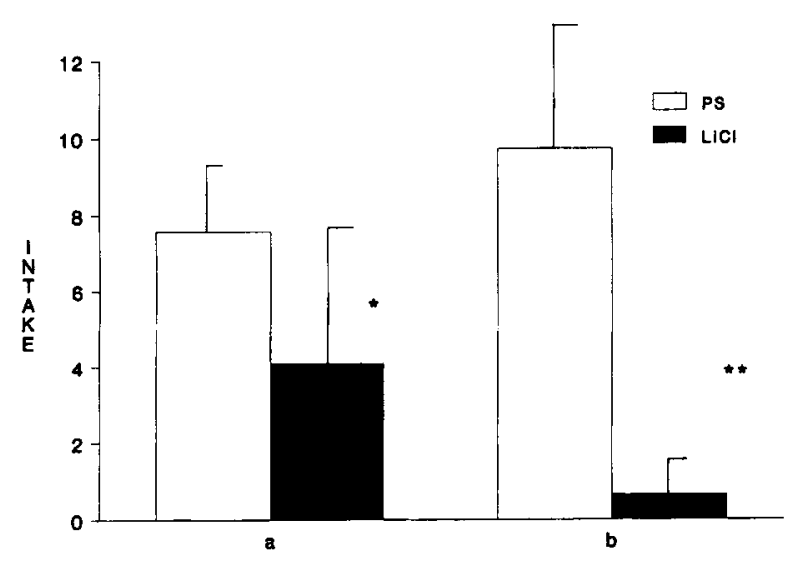

Figure 10. Mean intake $( \pm S D)$ of gustatory stimulus followed by intragastric administration of $\mathrm{LiCl}$ (filled bars) and neutral gustatory stimulus (open bars) during the choice test in Test 1 in the experimental group (a) and in the control group (b) of Experiment $4 .{ }^{*} p<.05 . \quad{ }^{* *} p<.001$. 


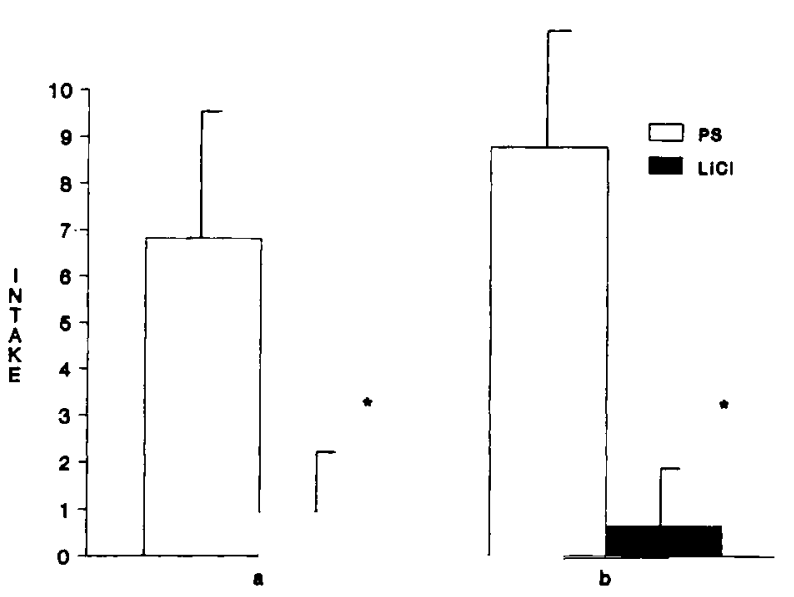

Figure 11. Mean intake $( \pm S D)$ of gustatory stimulus followed by intragastric administration of $\mathrm{LiCl}$ (filled bars) and neutral gustatory stimulus (open bars) during the choice test in Test 2 in the experimental group (a) and the control group (b) of Experiment $4 .{ }^{*} p<.001$.

perimental and control animals (experimental group, $t=2.41, p<.05$; control group, $t=10.67, p<.001$; see Figure 10). These results indicate that learning had occurred and that the animals were able to discriminate between the two stimuli on the basis of the consequences associated with each of them.

The results of the statistical analysis of the second phase of the choice test (Day 5) also demonstrated that parabrachial animals were able to learn to discriminate between the two stimuli, consuming significantly more of the gustatory stimulus associated with PS (experimental, $t=7.33$, $p<.001$; control, $t=7.39, p<.001$; see Figure 11), regardless of whether $Q$ or $S_{a}$ was associated with PS. This means that the PBNm-lesioned animals were able to learn a TAL task when they were presented with gustatory stimuli that they could distinguish, overcoming their initial preferences for $S_{a}$. These data support the hypothesis that, in PBNm-lesioned animals, the visceral pathway for $\mathrm{LiCl}$ processing is not disrupted.

\section{Discussion}

These results demonstrate that the disruption of TAL in animals with electrolytic lesions to the PBNm in Experiment 1 was not due to an overall deficit in the processing of stimuli involved in this learning task. Modifying the gustatory component was sufficient to make learning possible. The second concentration of $S_{a}$ and the third of $\mathrm{Q}$, distinguished by lesioned animals in the previous gustatory discrimination experiment (Experiment 3 ), were used properly in this TAL task. Moreover, the animals were able to overcome their initial tendencies to prefer $\mathrm{S}_{\mathrm{a}}$ (appetizing) over Q (aversive). The PBNm lesion apparently impaired the processing of gustatory information, as shown in Experiment 3, but it did not disrupt (as shown in Experiments 2 and 4) the visceral pathway responsible for the processing of intragastrically administered $\mathrm{LiCl}$, a chemical agent apparently pro- cessed via a humoral transmission pathway and the AP (Agüero, Arnedo, Gallo, \& Puerto, 1993a, 1993b; Arnedo, 1987; Arnedo, Gallo, Agüero, \& Puerto, 1990, 1991; Berger, Wise, \& Stein, 1973; Gallo, Arnedo, Agüero, \& Puerto, 1990; Ritter, McGlone, \& Kelley, 1980).

\section{GENERAL DISCUSSION}

The results of this study show that the gustatory system not only functions as a sensory system that transmits qualitative and quantitative information but is also involved in acquisition behaviors such as TAL.

Considered as a whole, these findings demonstrate that, although a simple gustatory discrimination task (Experiment 3 ) revealed only a partial deficit (lesioned subjects maintained some degree of sensitivity to qualitative and quantitative changes in the gustatory stimuli presented), a complex discrimination task revealed a considerable deficit when the stimuli presented were not differentiated, rendering the animals unable to solve the learning task (Experiment 1). In contrast, animals with electrolytic lesions to the PBNm were able to learn a TAL task when the gustatory stimuli used were distinguished (Experiment 4) or when the interstimulus delay was eliminated (Experiment 2). The facilitation of the gustatory cues through the use of stimuli that the lesioned animals were able to discriminate is sufficient in itself for animals to learn. Hence, these results appear to indicate that the deficit was caused by the impaired processing of one of the components of the association (i.e., the gustatory component), since the olfactory cues (or any other cue) were ineffective upon introducing the delay. Thus, the present findings have characterized the nature and origin of the deficit caused by the PBNm lesion. Animals with a brainstem PBNm lesion showed a deficit in the processing of gustatory information; the defect was apparently serious enough to disrupt learning with weak gustatory stimuli that these animals were probably unable to differentiate (Experiment 1). The gustatory discrimination deficit was thought to be the main obstacle to learning, since anatomical and electrophysiological studies have implicated this nucleus in the transmission of gustatory information toward more rostral structures of the CNS (Di Lorenzo \& Schwartzbaum, 1982a, 1982b; Norgren \& Leonard, 1972; Saper \& Loewy, 1980; Yamada et al., 1990) —one of them may be fundamental in "fine" gustatory discrimination or in the modulation of responses guided by "taste," as occurs in TAL.

At the thalamic and cortical levels, neurons have been detected that specifically codify gustatory intensity (Nomura \& Ogawa, 1985; Ogawa, Ito, \& Nomura, 1985; Pritchard, Hamilton, \& Norgren, 1989; Yamamoto, Matsuo, Kiyomitsu, \& Kitamura, 1989a, 1989b; Yamamoto, Yayama, Kato, \& Kawamura, 1984), responding differentially to changes in concentration of a particular gustatory stimulus. At the level of the PBNm, the connection with the thalamus or, alternatively, neurons functionally similar to the thalamic cells may have been destroyed, 
leading to the results obtained with $\mathrm{S}_{\mathrm{a}}$ without the animal detecting the changes in the stimulus as its concentration was increased.

Like earlier reports (Braun et al., 1982; Contreras, Beckstead, \& Norgren, 1982; Grill \& Norgren, 1978; Norgren, 1985), the present behavioral study demonstrates that the acceptance or rejection response to gustatory stimuli requires an intact brain stem. The discrimination and recognition of these gustatory stimuli may be processed further rostrally, whereas the decision to accept or reject it, based on a hedonic dimension, may take place in the brain stem.

However, this nucleus receives important afferent visceral projections from the caudalmost part of the NST (Contreras et al., 1982; Garcia et al., 1985; Grill, 1985; Leslie, Gwyn, \& Hopkins, 1982; Norgren, 1983; Scharon, 1984), as well as afferent connections from nuclei of the limbic system involved in the regulation of autonomic behavior (Bernard et al., 1993; Borsini \& Rolls, 1984; Ferssiwi et al., 1987; Fulwiler \& Saper, 1985; Horst, 1984; Shipley \& Geinisman, 1984; Takeuchi et al., 1987; Touzani, Ferssiwi, \& Velley, 1990; Van der Kooy, Koda, McGinty, Gerten, \& Bloom, 1984). Thus, the PBNm may participate in the transmission of visceral information. The disruption of learning may be due not only to a specifically gustatory deficit but also to disruption of the processing of intragastrically administered LiCl. Nevertheless, the fact that learning occurred with the use of gustatory stimuli that could be discriminated (Experiment 4) or when other alternative sensory cues were available (Experiment 2) rules out this possibility of the disruption of the processing of $\mathrm{LiCl}$. This interpretation is consonant with results obtained by Bechara et al. (1993). However, in their Experiment 2, these authors show that lesioning the $\mathrm{PBNl}$, with $\mathrm{LiCl}$ as the aversive stimulus and cherry or grape extracts as the gustatory stimuli, does not impair the acquisition of TAL. These results are similar to the findings in the present Experiment 2 in PBNm-lesioned animals. Both experiments involved the use of $\mathrm{LiCl}$, flavored solutions, and no interstimulus delay. However, in Bechara et al.'s study, the lesion was located in the PBNl, not in the PBNm, although, according to their stated coordinates, their lesion extended ventrally to the BC (see Figures $8 \mathrm{~b}$ and $8 \mathrm{c}$ in their article), an area very close to the electrolytic lesions we used in the PBNm. This may account for the similarities between their results and conclusions and ours. Likewise, the results in the present Experiment 2 are concordant with those of Experiment 1 in the Bechara et al. study: The PBNm lesion did not disrupt the nondelayed TAL task. However, the results are not entirely comparable, since Bechara et al. used morphine, not $\mathrm{LiCl}$, as the aversive stimulus. Moreover, many authors have described the behavioral pattern exhibited after $\mathrm{LiCl}$ is administered intragastrically (Bernstein \& Goehler, 1983; Blier \& Montigny, 1985; Di Lorenzo, 1988a; Kurtz \& Levitsky, 1983; West, Greenwood, \& Marshall, 1987): After injection of the toxic substance, the animals become almost completely inactive, lying on the floor of the cage with head bowed between forelegs, show- ing occasional spasmodic movements, and responding weakly, if at all, to stimuli. This pattern of behavior was seen in both lesioned and control subjects in our experiments shortly after $\mathrm{LiCl}$ injection. This means that $\mathrm{LiCl}$ can be processed through pathways other than the PBNm.

The results obtained in Experiment 4 rule out the disruption of the transmission of visceral information on $\mathrm{LiCl}$, since the PBNm-lesioned animals readily learned to discriminate between the two stimuli and even overcame their initial preference for $S_{a}$. This conclusion is compatible with previous reports that demonstrated the processing of certain chemical agents, including peripherally administered $\mathrm{LiCl}$, to take place via the circulatory system and the AP (Gallo et al., 1990; Rabin \& Hunt, 1986; Ritter et al., 1980), and via the PBNl (Agüero, 1990; Agüero et al., 1993a, 1993b), an area far from the site specifically destroyed in the present experiments. However, this is not the only potential mechanism for the processing of visceral information. A number of studies have shown that the vagus nerve may, in some cases, act as a pathway for visceral information (Arnedo et al., 1990, 1991). The significance of visceral information processed by the NST and the PBNm, and its relationship with TAL, will be examined in a subsequent article (Agüero, Gallo, Arnedo, Molina, \& Puerto, 1996).

Alternatively, the learning deficit caused by the PBNm lesion in Experiment 1 may have been due to disruption of the integration or association that may have been established in this pontine nucleus. The fact that the PBNmlesioned animals were able to learn nondelayed tasks (Experiment 2) and delayed tasks with potent gustatory stimuli (Experiment 4) does not support the hypothesis of integration. Our results are also compatible with those of Bechara et al. (1993), although differences in the location of the lesion and procedural conditions make comparison difficult. In addition, the findings of Grill and Norgren (1978) in animals decerebrated at the supracollicular level contradict this hypothesis of integration, since, even though the PBNm was intact in these animals, they were unable to learn the association between saccharine and $\mathrm{LiCl}$, whereas intact animals learned this association readily. However, Grill and Norgren noted that the animals were able to discriminate well between several types of gustatory stimulus, such as bitter and sweet tastes.

The results obtained in Experiment 4 also rule out a possible memory deficit, which may have been plausible on the basis of earlier results of Experiment 2. In Experiment 4 , the animals were subjected to a delayed TAL task yet were still able to learn.

In summary, our data are consonant with those of other studies that have shown PBNm lesions to disrupt learning in delayed tasks (Di Lorenzo, 1988a; Flynn, Grill, Schulkin, \& Norgren, 1991; Reilly et al., 1993; Spector et al., 1993; Spector et al., 1992; Yamamoto \& Fujimoto, 1991). However, in our experiments and in other studies (Bechara et al., 1993; Di Lorenzo, 1988a; Yamamoto et al., 1994), the disruption disappeared when interstimulus delay was removed (Experiment 2). In con- 
trast, experiments performed by Spector et al. (1992) showed that contiguity between stimuli (no delay) did not favor learning in PBNm-lesioned animals. Although there is no evidence that might explain these discrepancies, the gustatory and olfactory stimuli used by these authors may have been too weak to permit learning in a nondelayed task. Finally, the dependent variable used by these authors (oropharyngeal responses and approach/ avoidance responses) may not be equivalent to the measurement of liquids consumed, as used in our experiments.

\section{REFERENCES}

AAS, J. E., \& Brodal, P. (1988). Demonstration of topographically organized projections from the hypothalamus to the pontine nuclei: An experimental anatomical study in the cat. Journal of Comparative Neurology, 268, 313-332.

Agüero, A. (1990). Participación del núcleo parabraquial troncoencefálico en el aprendizaje interoceptivo: Disociación comportamental de los diferentes subnúcleos (medial y lateral) en el procesamiento visceral y gustativo [Role of the brainstem parabrachial nucleus in taste aversion learning: Behavioral dissociation of the medial and lateral nuclei in visceral and gustatory processing]. Unpublished doctoral dissertation, Universidad de Granada.

Agüero, A., Arnedo, M., Gallo, M., \& Puerto, A. (1993a). The functional relevance of the lateral parabrachial nucleus in lithium chloride-induced aversion learning. Pharmacology, Biochemistry \& Behavior, 45, 973-978.

Agüero, A., Arnedo, M., Gallo, M., \& Puerto, A. (1993b). Lesions of the parabrachial nuclei disrupt aversion learning induced by electrical stimulation of the area postrema. Brain Research Bulletin, 30, 585-592.

Agüero, A., Gallo, M., Arnedo, M., Molina, F., \& Puerto, A. (1996). The functional relevance of medial parabrachial nucleus $(P B N m$ ) in intragastric sodium chloride-induced short-term (concurrent) aversion learning. Manuscript submitted for publication.

ARNeDO, M. (1987). Bases biológicas del Aprendizaje Interoceptivo: Una disociación comportamental de los sistemas periféricos implicados en procesamiento visceral [Biological basis of taste aversion learning: A behavioral dissociation of the peripheral systems involved in visceral processing]. Unpublished doctoral dissertation, Universidad de Granada.

Arnedo, M., Gallo, M., Agüero, A., \& Puerto, A. (1990). Effects of medullary afferent vagal axotomy and area postrema lesions on short-term NaCl-induced taste aversion learning. Physiology \& Behavior, 47, 1067-1074.

Arnedo, M., Gallo, M., Agüero, A., \& Puerto, A. (1991). Differential effects of subdiaphragmatic vagotomy on $\mathrm{NaCl}$-induced aversion learning. Behavioral \& Neural Biology, 55, 141-155.

ASHE, J. H., \& NaChMan, M. (1980). Neural mechanisms in taste aversion learning. Progress in Psychobiology \& Physiological Psychology, 9, 233-262.

Bechara, A., Martin, G. M., Pridgar, A., \& Van der Kooy, D. (1993). The parabrachial nucleus: A brain stem substrate critical for mediating the aversive motivational effects of morphine. Behavioral Neuroscience, 107, 147-160.

Beckstead, R. M., Morse, J. R., \& Norgren, R. (1980). The nucleus of the solitary tract in the monkey: Projections to the thalamus and brainstem nuclei. Journal of Comparative Neurology, 190, 259-282.

BENJAMIN, R. M. (1955). Cortical taste mechanisms studied by two different test procedures. Journal of Comparative \& Physiological Psychology, 48, 119-123.

Berger, B. D., WiSE, C. D., \& STEIN, L. (1973). Area postrema damage and bait shyness. Journal of Comparative \& Physiological Psychology, 82, 475-479.

Bernard, J. F., Alden, M., \& Besson, J. M. (1993). The organization of the efferent projections from the pontine parabrachial area to the amygdaloid complex: A phaseolus vulgaris leucoaglutinin (PHA-L) study in the rat. Journal of Comparative Neurology, 329, 201-229.

Bernstein, I. L., \& Goehler, L. E. (1983). Chronic lithium chloride infusions: Conditioned suppression of food intake and preference. Behavioral Neuroscience, 97, 290-298.

Blier, P., \& MONTIGNY, C. (1985). Short-term lithium administration enhances serotonergic neurotransmission: Electrophysiological evidence in the rat CNS. European Journal of Pharmacology, 113, 69-77.

BLOCK, C. H., \& EsTES, M. L. (1990). The cytoarchitectural organization of the human parabrachial nuclear complex. Brain Research Bulletin, 24, 617-626.

Block, C. H., Hoffman, G., \& Kapp, B. S. (1989). Peptide-containing pathways from the parabrachial complex to the central nucleus of the amygdala. Peptides, 10, 465-467.

Block, C. H., \& Schwartbaum, J. S. (1983). Ascending efferent projections of the gustatory parabrachial nuclei in the rabbit. Brain Research, 259, 1-11.

BORSINI, F., \& ROLLS, E. T. (1984). Role of noradrenaline and serotonin in the basolateral regions of the amygdala in food preferences and learned taste aversions in the cat. Physiology \& Behavior, 33, 37-45.

Bouton, M. E., \& Whiting, M. R. (1982). Simultaneous odor-taste and taste-taste compounds in poison-avoidance learning. Learning \& Motivation, 13, 472-494.

Braun, J. J., Lasiter, P. S., \& Kiefer, S. W. (1982). The gustatory neocortex of the rat. Physiological Psychology, 10, 13-45.

Coburn, K. L., Garcia, J., \& Kiefer, S. W. (1984). Taste potentiation of poisoned odor by temporal contiguity. Behavioral Neuroscience, 98, 813-819.

Contreras, R. J., Beckstead, R. M., \& Norgren, R. (1982). The central projections of the trigeminal, facial, glossopharyngeal and vagus nerves: An autoradiographic study in the rat. Journal of the Autonomic Nervous System, 6, 303-322.

Contreras, R. J., Beckstead, R. M., \& Norgren, R. (1984). Activity in the salt fibers: Peripheral mechanism for mediating changes in the salt intake. Chemical Senses, 8, 275-287.

Contreras, R. J., \& Smith, J. C. (1990). NaCl concentration alters temporal patterns of drinking and eating by rats. Chemical Senses, $15,295-310$

Deutsch, J. A., \& Koopman, H. S. (1973). Preference enhancement to alcohol by passive exposure. Science, 179, 1242-1243.

Di LoRENZO, P. M. (1988a). Long-delay in rats with parabrachial pontine lesions. Chemical Senses, 13, 219-229.

Di LORENZo, P. M. (1988b). Taste responses in the parabrachial pons of decerebrate rats. Journal of Neurophysiology, 59, 1871-1888.

Di LoRenzo, P. M. (1990). Corticofugal influence on taste responses in the parabrachial pons of the rat. Brain Research, 530, 73-84.

Di LoRenZo, P. M., \& GARCIA, J. (1985). Olfactory responses in the gustatory area of the parabrachial pons. Brain Research Bulletin, 15, 673-676.

Di Lorenzo, P. M., \& Schwartzbaum, J. S. (1982a). Coding of gustatory information in the pontine parabrachial nuclei of the rabbit: Magnitude of neural response. Brain Research, 251, 226-244.

Di Lorenzo, P. M., \& Schwartzbaum, J. S. (1982b). Coding of gustatory information in the pontine parabrachial nuclei of the rabbit: Temporal patterns of neural response. Brain Research, 251, 245257.

Doty, R. L., Gregor, T. P., \& Settle, R. G. (1986). Influence of intertrial interval and sniff-bottle volume on phenyl ethyl alcohol odor detection thresholds. Chemical Senses, 11, 259-264.

ElizALDE, G., \& SCLAFANI, A. (1988). Starch-based conditioned flavor preferences in rats: Influence of taste, calories and CS-US delay. $A p$ petite, 11, 179-200.

Fernandez-Ruiz, J., Miranda, M. I., Bermudez-Rattoni, F., \& DRUCKER-Colin, R. (1993). Effects of catecholaminergic depletion of the amygdala and insular cortex on the potentiation of odor by taste aversions. Behavioral \& Neural Biology, 60, 189-191.

Ferssiwl, A., CARDo, B., \& VelLEY, L. (1987). Electrical self-stimulation in the parabrachial area is depressed after ibotenic acid lesion of the lateral hypothalamus. Behavioural Brain Research, 25, 109-116.

FlynN, F. W., Grill, H. J., Schulkin, J., \& Norgren, R. (1991). Central gustatory lesions: II. Effects on sodium appetite, taste aversion learning, and feeding behaviors. Behavioral Neuroscience, 105, 944-954.

Flynn, F. W., Grill, H. J., Schwartz, G. J., \& Norgren, R. (1991). Central gustatory lesions: I. Preference and taste reactivity tests. $B e$ havioral Neuroscience, 105, 933-943. 
Frank, M. E., \& Nowlis, G. H. (1989). Learned aversions and taste qualities in hamsters. Chemical Senses, 14, 379-394.

Fulwiler, C. E., \& SAPER, C. B. (1984). Subnuclear organization of efferent connections of the parabrachial nucleus in the rat. Brain Research Review, 7, 229-259.

Fulwiler, C. E., \& SAPER, C. B. (1985). Cholecystokinin-immunoreactive innervation of the ventromedial hypothalamus in the rat: Possible substrate for autonomic regulation of feeding. Neuroscience Letters, 53, 289-296.

Gallo, M., Arnedo, M., Agüero, A., \& Puerto, A. (1990). The functional relevance of the area postrema in drug-induced taste aversion learning. Pharmacology, Biochemistry \& Behavior, 35, 543-551.

GARCIA, J., \& BRETT, L. P. (1977). Conditioned responses to food odor and taste in rats and wild predators. In M. Kare \& O. Maller (Eds.), The chemical senses and nutrition (pp. 277-289). New York: Academic Press.

Garcia, J., \& Koelling, R. A. (1966). Relation of cue to consequence in avoidance learning. Psychonomic Science, 4, 123-124.

Garcia, J., Lasitter, P. A., Bermudez-Rattoni, F., \& Deems, D. A. (1985). A general theory of aversion learning. In N. S. Braveman \& P. Bronstein (Eds.), Experimental assessments and clinical applications of conditioned food aversions (Annals of the New York Academy of Sciences, Vol. 443, pp. 8-22). New York: New York Academy of Sciences.

Garcia, J., \& RusiniaK, K. W. (1980). What the nose learns from the mouth. In D. Müller-Schwarze \& R. M. Silverstein (Eds.), Chemical signals (pp. 141-155). New York: Plenum.

GASTON, K. E. (1978). Brain mechanisms of conditioned taste aversion learning: A review of the literature. Physiological Psychology, 6, 340-353.

Grigson, P. S., Spector, A. C., \& Norgren, R. (1994). Lesions of the pontine parabrachial nuclei eliminate successive negative contrast effects in rats. Behavioral Neuroscience, 108, 714-723.

GRILL, H. J. (1985). Introduction: Physiological mechanisms in conditioned taste aversions. In N. S. Braveman \& P. Bronstein (Eds.), Experimental assessments and clinical applications of conditioned food aversions (Annals of the New York Academy of Sciences, Vol. 443, pp. 67-89). New York: New York Academy of Sciences.

Grill, H. J., \& Norgren, R. (1978). Chronic decerebrate rats demonstrate satiation but not bait-shyness. Science, 201, 267-269.

Grill, H. J., Schulkin, J., \& FlynN, F. W. (1986). Sodium homeostasis in chronic decerebrate rats. Behavioral Neuroscience, 100, 536-543.

Hankins, W. G., Garcia, J., \& Rusiniak, K. W. (1973). Dissociation of odor and taste in bait-shyness. Behavioral Biology, 8, 407-419.

Hayama, T., \& OGaWA, H. (1987). Electrophysiological evidence of collateral projections of parabrachio-thalamic relay neurons. Neuroscience Letters, 83, 95-100.

Herman, G. E., Kohlerman, N. J., \& Rogers, R. C. (1983). Hepaticvagal and gustatory afferent interactions in the brainstem of the rat. Journal of the Autonomic Nervous System, 9, 477-495.

Herness, M. S., \& Pfaffman, C. (1986). Generalization of conditioned taste aversions in hamsters: Evidence for multiple bitter receptor sites. Chemical Senses, 11, 347-360.

Hill, D. L., \& AlmLI, C. R. (1983). Parabrachial nuclei damage in infant rats produces residual deficits in gustatory preferences/aversions and sodium appetite. Developmental Psychobiology, 16, 519-533.

HoRst, G. J. (1984). Descending pathways from hypothalamus to dorsal motor vagus and ambiguous nuclei in the rat. Journal of the $\mathrm{Au}$ tonomic Nervous System, 11, 59-75.

$J_{A C Q U 1 N}, M$. F. (1983). Gustation and ingestive behavior in the rat. Behavioral Neuroscience, 97, 98-109.

Johanson, I. B., \& Shapiro, E. G. (1986). Intake and behavioral responsiveness to taste stimuli in infant rats from 1 to 15 days of age. Developmental Psychobiology, 19, 593-606.

Kemble, E. D., Studelska, D. R., \& Schmidt, M. K. (1979). Effects of central amygdaloid nucleus lesions on ingestion, taste reactivity, exploration and taste aversion. Physiology \& Behavior, 22, 789-793.

KIEFER, S. W. (1985). Neural mediation of conditioned food aversions. In N. S. Braveman \& P. Bronstein (Eds.), Experimental assessments and clinical applications of conditioned food aversions (Annals of the New York Academy of Sciences, Vol. 443, pp. 100-110). New York: New York Academy of Sciences.
Kiefer, S. W., \& Braun, J. J. (1979). Acquisition of taste avoidance habits in rats lacking gustatory neocortex. Physiological Psychology, 7, 245-250.

KiefER, S. W., \& LAWrence, G. J. (1988). The sweet-bitter taste of alcohol: Aversion generalization to various sweet quinine mixtures in the rat. Chemical Senses, 13, 633-641.

KIEFER, S. W., LEACH, L. R., \& BRAUN, J. J. (1984a). Neonatal ablations of the gustatory neocortex in the rat: Taste aversion learning and taste reactivity. Behavioral Neuroscience, 98, 804-812.

Kiefer, S. W., LeACh, L. R., \& BRAUN, J. J. (1984b). Taste agnosia following gustatory neocortex ablation: Dissociation from odor and generality across taste qualities. Behavioral Neuroscience, 98, 590-608.

Kiefer, S. W., Rusiniak, K. W., \& Garcia, J. (1982). Flavor-illness aversions: Gustatory neocortex ablations disrupt taste but not tastepotentiated odor cues. Journal of Comparative \& Physiological Psychology, 96, 540-548.

KING, G. W. (1980). Topology of ascending brainstem projections to nucleus parabrachialis in the cat. Journal of Comparative Neurology, 191, 615-638.

Kurtz, E. M., \& Levitsky, D. A. (1983). Lithium chloride and avoidance of novel places. Behavioral Neuroscience, 97, 345-351.

LASITER, P. S., \& GlanZMAN, D. L. (1983). Axon collaterals of pontine taste area neurons project to the posterior ventromedial thalamic nucleus and to the gustatory neocortex. Brain Research, 258, 299-304.

Lasiter, P. S., Glanzman, D. L., \& Mensah, P. A. (1982). Direct connectivity between pontine taste areas and gustatory neocortex in rat. Brain Research, 234, 111-121.

Leslie, R. A., GwYn, D. G., \& Hopkins, D. A. (1982). The central distribution of the cervical vagus nerve and gastric afferent and efferent projections in the rat. Brain Research Bulletin, 8, 37-43.

Miller, M. G., \& Teates, J. F. (1986). The role of taste in dietary selfselection in rats. Behavioral Neuroscience, 100, 399-409.

Milner, T. A., Joh, T. H., Miller, R. J., \& Pickel, V. M. (1984). Substance $P$, neurotensin, enkephalin, and catecholamine-synthesizing enzymes: Light microscopic localizations compared with autoradiographic label in solitary efferents to the rat parabrachial region. Journal of Comparative Neurology, 226, 434-447.

Moga, M. M., \& GRAY, T. S. (1985a). Evidence for corticotropinreleasing factor, neurotensin, and somatostatin in the neural pathway from the central nucleus of the amygdala to the parabrachial nucleus. Journal of Comparative Neurology, 241, 275-284.

Moga, M. M., \& Gray, T. S. (1985b). Peptidergic efferents from the intercalated nuclei of the amygdala to the parabrachial nucleus in the rat. Neuroscience, 61, 13-18.

Moga, M. M., SAPER, C. B., \& Gray, T. S. (1989). Bed nucleus of the stria terminalis: Cytoarchitecture, immunohistochemistry, and projection to the parabrachial nucleus in the rat. Journal of Comparative Neurology, 283, 315-332.

Nagal, K., Ino, H., Yamamoto, H., Nakagawa, H., Yamamoto, M., Tohyama, M., Shirosaka, S., Shiotani, Y., Inagaki, S., \& KITOH, S. (1987). Lesions in the lateral part of the dorsal parabrachial nucleus caused hyperphagia and obesity. Journal of Clinical Biochemistry \& Nutrition, 3, 103-112.

NishiJo, H., \& Norgren, R. (1991). Parabrachial gustatory neural activity during licking by rats. Journal of Neurophysiology, 66, 974-985.

Nomura, T., \& OGaWA, H. (1985). The taste and mechanical response properties of neurons in the parvicellular part of the thalamic posteromedial ventral nucleus of the rat. Neuroscience Research, 3, 91-105.

NORGREN, R. (1976). Taste pathways to hypothalamus and amygdala. Journal of Comparative Neurology, 166, 17-30.

NORGREN, R. (1983). Afferent interactions of cranial nerves involved in ingestion. Journal of the Autonomic Nervous System, 9, 67-77.

NORGREN, R. (1985). Taste and the autonomic nervous system. Chemical Senses, 10, 143-161.

Norgren, R., \& LeONARD, C. M. (1972). Ascending central gustatory pathways. Journal of Comparative Neurology, 150, 217-238.

Novin, D., Rogers, R. C., \& Herman, G. (1981). Visceral afferent and efferent connections in the brain. Diabetologia, 20, 331-336.

Ogawa, H., Hayama, T., \& Ito, S. (1984). Localization and taste responses of parabrachio-thalamic relay neurons in rats. Experimental Neurology, 83, 507-517.

Ogawa, H., Hayama, T., \& Ito, S. (1987). Response properties of 
parabrachio-thalamic taste and mechanoreceptive neurons in rats. Experimental Brain Research, 68, 449-457.

OGawa, H., Imoto, T., \& Hayama, T. (1984). Responsiveness of solitarioparabrachial relay neurons to taste and mechanical stimulation applied to the oral cavity in rats. Experimental Brain Research, 54, 349-358.

Ogawa, H., Ito, S., \& Nomura, T. (1985). Two distinct projection areas from tongue nerves in the frontal operculum of macaque monkeys as revealed with evoked potential mapping. Neuroscience Research, $\mathbf{2}$, 447-459.

Palmerino, C. C., Rusiniak, K. W., \& Garcia, J. (1980). Flavor-illness aversions: The peculiar roles of odor and taste in memory for poison. Science, 208, 753-755.

Pammer, C. S., Fodor, M., \& Palkovits, M. (1988). Localization of corticotropin-releasing factor, somatostatin, and vasoactive intestinal polypeptide in the parabrachial nuclei of the human brain. Journal of Neuroscience Research, 20, 109-114.

PANHUBER, H. (1982). Effect of odor quality and intensity on conditioned odor aversion learning in the rat. Physiology \& Behavior, 28, 149-154.

Pellegrino, L. J., Pelley, A. S., \& Cushman, A. J. (1979). Stereotaxic atlas of the rat brain. New York: Plenum.

Perroto, R. S., \& SCOTT, T. R. (1976). Gustatory neural coding in the pons. Brain Research, 110, 283-300.

PfafFman, C. (1952). Taste preference and aversion following lingual denervation. Journal of Comparative \& Physiological Psychology, 45, 393-401.

Pfaffman, C., Frank, M., \& Norgren, R. (1979). Neural mechanisms and behavioral aspects of taste. Annual Review of Psychology, 30, 283-325.

Pritchard, T. C., Hamilton, R. B., \& Norgren, R. (1989). Neural coding of gustatory information in the thalamus of macaca mulatta. Journal of Neurophysiology, 61, 1-14.

Pritchard, T. C., Reilly, S., Hamilton, R. B., \& Norgren, R. (1994) Taste preference of old world monkeys: I. A single-bottle preference test. Physiology \& Behavior, 55, 477-481.

Rabin, B. M., \& Hunt, W. A. (1986). Mechanisms of radiation-induced conditioned taste aversion learning. Neuroscience \& Biobehavioral Reviews, 10, 55-65.

Radhakrishman, V., \& Sharma, K. N. (1986). Effect of selective gastric vagotomy on gustatory behavior in rats. Journal of the Autonomic Nervous System, 16, 127-136.

Reil.ly, S., Grigson, P. S., \& Norgren, R. (1993). Parabrachial nucleus lesion evidence supporting an associative deficit. Behavioral Neuroscience, 107, 1005-1017.

Ritter, S., McGlone, J. J., \& Kelley, K. W. (1980). Absence of lithium-induced taste aversion after area postrema lesion. Brain Research, 201, 501-506

Rusiniak, K. W., Garcia, J., Palmerino, C. C., \& Cabral, R. J. (1983). Developmental flavor experience affects utilization of odor, not taste in toxiphobic conditioning. Behavioral \& Neural Biology, $39,160-180$

Rusiniak, K. W., Hawkins, W. G., Garcia, J., \& Brett, L. P. (1979). Flavor-illness aversions: Potentiation odor by taste in rats. Behavioral \& Neural Biology, 25, 1-17.

SAPER, C. B. (1982). Reciprocal parabrachial-cortical connections in the rat. Brain Research, 242, 33-40.

SAPER, C. B., \& LOEWY, A. D. (1980). Efferent connections of the parabrachial nucleus in the rat. Brain Research, 197, 291-317.

Schafe, G. E., SeEley, R. J., \& Bernstein, I. L. (1995). Forebrain contribution to the induction of a cellular correlate of conditioned taste aversion in the nucleus of the solitary tract. Journal of Neuroscience, 15, 6789-6796

SCharon, S. L. (1984). Vagal and gastric connections to the central nervous system determined by transport of horseradish peroxidase. Brain Research, 13, 573-585.

SCHNEIDER, K., \& Whote, K. (1979). The contribution of naso-oral and postingestional factors in taste aversion learning in the rat. Behavioral $\&$ Neural Biology, 25, 30-38.

Schwaber, J. S., Sternini, C., Brechna, N. C., Rogers, W. T., \& CARD, J. P. (1988). Neurons containing calcitonin gene-related peptide in the parabrachial nucleus project to the central nucleus of the amygdala. Journal of Comparative Neurology, 270, 416-426.
SCHWARTZ, G. J., \& GrILL, H. J. (1984). Relationships between taste reactivity and intake in the neurologically intact rat. Chemical Senses, 9, 249-272

SChWARTZBaum, J. G. (1983). Electrophysiology of taste-mediated functions in parabrachial nuclei of behaving rabbit. Brain Research, $11,61-89$.

SCOTT, T. R., \& PerRoto, R. S. (1980). Intensity coding in pontine taste area: Gustatory information is processed similarly throughout rat's brain stem. Journal of Neurophysiology, 44, 739-750.

Seligman, M. E. P., \& Hager, J. L. (1972). Biological boundaries of learning: The sauce-bernaise syndrome. Psychology Today, 6, 59-61.

ShapIRo, E. G., \& Johanson, I. B. (1985). The development of aversive responses to quinine in hyperthyroid rats. Behavioral \& Neural Biology, 43, 274-286.

Sharma, K. N., Jacobs, H. L., Gopal, V., \& Dua-Sharma, S. (1977). Neural state/taste interactions in food intake: Behavioral and physiological evidence for gastric/taste modulation. In M. Kare \& O. Maller (Eds.), The chemical senses and nutrition (pp. 167-188). New York: Academic Press.

Shipley, M. T., \& Geinisman, Y. (1984). Anatomical evidence for convergence of olfactory, gustatory and visceral efferent pathways in mouse cerebral cortex. Brain Research, 12, 221-226.

ShIPLEY, M. T., \& SANDERS, M. S. (1982). Special senses are really special: Evidence for reciprocal, bilateral pathway between insular cortex and nucleus parabrachialis. Brain Research, 8, 493-501.

SimbaYl, L. C. (1987). Effects of anterior basolateral amygdala lesions of taste aversions produced by high and low oral doses of $\mathrm{LiCl}$ and lactose in the rat. Behavioural Brain Research 25, 131-142.

Simbayi, L. C., Boakes, R. A., \& Burton, M. J. (1986). Effects of basolateral amygdala lesions on taste aversions produced by lactose and lithium chloride in the rat. Behavioral Neuroscience, 100, 455-465.

Smith, D. V., Van Buskirk, R. L., Travers, J. B., \& Bieber, S. L. (1983a). Coding of taste stimuli by hamster brain stem neurons. Journal of Neurophysiology, 50, 541-558.

Smith, D. V., Van Buskirk, R. L., Travers, J. B., \& Bieber, S. L. (1983b). Gustatory neuron types in hamster brain stem. Journal of Neurophysiology, 50, 522-540.

Spector, A. C., Grill, H. J., \& Norgren, R. (1993). Concentrationdependent licking of sucrose and sodium chloride in rats with parabrachial gustatory lesions. Physiology \& Behavior, 53, 277-283.

Spector, A. C., Norgren, R., \& Grill, J. (1992). Parabrachial lesions impair taste aversion learning in rats. Behavioral Neuroscience, 106, 147-161.

Staubli, V., Schottler, F., \& Nejat-Bina, D. (1987). Role of dorsomedial thalamic nucleus and piriform cortex in processing olfactory information. Behavioural Brain Research, 25, 117-129.

St. John, S. J., Garcea, M., \& Spector, A. C. (1994). Combined, but not single, gustatory nerve transection substantially alters tasteguided licking behavior to quinine in rats. Behavioral Neuroscience, 108, 131-140.

Takeuchi, Y., McLean, J. H., \& Hopkins, D. A. (1982). Reciprocal connection between the amygdala and parabrachial nuclei. Brain Research, 239, 583-588.

Takeuchi, Y., Takahashi, O., Satoda, T., \& Matsuchima, R. (1987). Long dendrites of the parabrachial nucleus projecting to the amygdala: A horseradish peroxidase and Golgi study in the cat. Experimental Neurology, 96, 203-207.

Touzani, K., Ferssiwi, A., \& Velley, L. (1990). Localization of lateral hypothalamic neurons projecting to the medial part of the parabrachial area of the rat. Neuroscience Letters, 114, 17-21.

Travers, J. B. (1988). Efferent projections from the anterior nucleus of the solitary tract of the hamster. Brain Research, 457, 1-11.

Travers, S. P., Pfaffman, C., \& Norgren, R. (1986). Convergence of lingual and palatal gustatory neural activity in the nucleus of the solitary tract. Brain Research, 365, 305-320.

Travers, S. P., \& SMITH, D. V. (1984). Responsiveness of neurons in the hamster parabrachial nuclei to taste mixtures. Journal of General Physiology, 84, 221-250.

VAN BUSKIRK, R. L. (1981). The role of odor in the maintenance of flavor aversion. Physiology \& Behavior, 27, 189-193.

Van der Kooy, D., Koda, L. Y., McGinty, J., Gerten, C. R., \& BLoom, F. E. (1984). The organization of projections from the cor- 
tex, amygdala, and hypothalamus to the nucleus of the solitary tract in the rat. Journal of Comparative Neurology, 224, 1-24.

VOSHART, K., \& VAN DER KOOY, D. (1981). The organization of the efferent projections of the parabrachial nucleus to the forebrain in the rat: A retrograde fluorescent double-labeling study. Brain Research, 212, 271-286.

Weingarten, H. P., \& Martin, G. M. (1989). Mechanisms of conditioned meal initiation. Physiology \& Behavior, 45, 735-740.

West, D. B., Greenwood, M. R. C., \& Marshall, K. A. (1987). Lithium chloride, cholecystokinin and meal patterns: Evidence that cholecystokinin suppresses meal size in rats without causing malaise. Appetite, 8, 221-227.

WoNG, R. (1985). Saccharin preference of hamsters, gerbils and rats in the two-food situation. Behavioural Processes, 10, 87-89.

Yamada, S., Ohsima, T., Oda, H., Adachi, M., \& Satoh, T. (1990). Synchronized discharge of taste neurons recorded simultaneously in rat parabrachial nucleus. Journal of Neurophysiology, 63, 294-302.

Yамамото, T., \& Fujimoto, Y. (1991). Brain mechanisms of taste aversion learning in the rat. Brain Research Bulletin, 27, 403-408.

Yamamoto, T., Matsuo, R., \& Kawamura, Y. (1980). Localization of cortical gustatory area in rats and its role in taste discrimination. Journal of Neurophysiology, 44, 440-455.

Yamamoto, T., Matsuo, R., Kiyomitsu, Y., \& Kitamura, R. (1989a).
Sensory inputs from the oral region to the cerebral cortex in behaving rats: An analysis of unit responses in cortical somatosensory and taste areas during ingestive behavior. Journal of Neurophysiology, 60, 1303-1321.

Yamamoto, T., Matsuo, R., Kiyomitsu, Y., \& KitamuRa, R. (1989b). Taste responses of cortical neurons in freely ingesting rats. Journal of Neurophysiology, 61, 1244-1258.

Yamamoto, T., Shimura, T,, Sako, N., Yasohima, Y., \& Sakai, N. (1994). Neural substrates for conditioned taste aversion in the rat. Behavioural Brain Research, 65, 123-137.

Yamamoto, T., Yayama, N., Kato, T., \& Kawamura, Y. (1984). Gustatory responses of cortical neurons in rats: I. Responses characteristics. Journal of Neurophysiology, 51, 616-635.

Yasui, Y., Itoh, K., Takada, M., Mitani, A., Kaneko, T., \& MIzUNO, N. (1985). Direct cortical projections to the parabrachial nucleus in the cat. Journal of Comparative Neurology, 234, 77-86.

Yonemura, K., TakeI, M., Kinitake, T., \& Ishiko, N. (1989). The ability of gustatory stimuli to modify the cardiac sympathetic and vagus nerve activities. Neuroscience Letters, 97, 85-97.

(Manuscript received December 6, 1995; revision accepted for publication July 18, 1996.) 